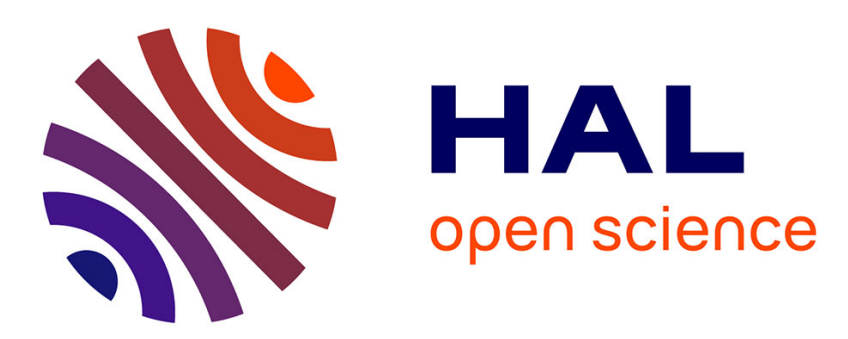

\title{
Characterization of the field saturated hydraulic conductivity on a hillslope: measurement techniques, data sensitivity analysis and spatial correlation modelling
}

C. Fallico, E. Migliari, S. Troisi

\section{To cite this version:}

C. Fallico, E. Migliari, S. Troisi. Characterization of the field saturated hydraulic conductivity on a hillslope: measurement techniques, data sensitivity analysis and spatial correlation modelling. Hydrology and Earth System Sciences Discussions, 2005, 2 (4), pp.1247-1298. hal-00298680

\section{HAL Id: hal-00298680 \\ https://hal.science/hal-00298680}

Submitted on 28 Jul 2005

HAL is a multi-disciplinary open access archive for the deposit and dissemination of scientific research documents, whether they are published or not. The documents may come from teaching and research institutions in France or abroad, or from public or private research centers.
L'archive ouverte pluridisciplinaire HAL, est destinée au dépôt et à la diffusion de documents scientifiques de niveau recherche, publiés ou non, émanant des établissements d'enseignement et de recherche français ou étrangers, des laboratoires publics ou privés. 
Hydrol. Earth Sys. Sci. Discuss., 2, 1247-1298, 2005 www.copernicus.org/EGU/hess/hessd/2/1247/

SRef-ID: 1812-2116/hessd/2005-2-1247

European Geosciences Union
Hydrology and Earth System Sciences Discussions

Papers published in Hydrology and Earth System Sciences Discussions are under open-access review for the journal Hydrology and Earth System Sciences

\section{Characterization of the field saturated hydraulic conductivity on a hillslope: measurement techniques, data sensitivity analysis and spatial correlation modelling}

C. Fallico, E. Migliari, and S. Troisi

Department of Soil Conservation, University of Calabria, 87036 Rende (CS), Italy

Received: 7 June 2005 - Accepted: 25 June 2005 - Published: 28 July 2005

Correspondence to: C. Fallico (fallico@dds.unical.it)

(C) 2005 Author(s). This work is licensed under a Creative Commons License.

HESSD

2, 1247-1298, 2005

Characterization of field saturated

hydraulic conductivity

C. Fallico et al.

Title Page

Abstract

Introduction

Conclusions

References

Tables

Figures

14

$\rightarrow$

4

Back

Close

Full Screen / Esc

Print Version

Interactive Discussion 


\section{Abstract}

In the context of studies aiming at the estimation of effective parameters for unsaturated zone modelling, this work tackles the problem of experimental data quality, considering the large collection of data gathered at an experimental site equipped for unsaturated zone hydraulic monitoring in the alluvial basin of a Calabrian river, in the South of Italy.

Focusing attention on field saturated hydraulic conductivity, the in-site measurement techniques by tension disc and pressure ring infiltrometers are considered, pointing out the main indications for the correct use of each measuring approach; laboratory techniques are also considered.

Statistical data analysis showed that the measurements performed by tension disc infiltrometer supplied values of hydraulic conductivity which are on average lower and more homogeneous than the values provided by the other measurement techniques considered.

Sensitivity analysis was then carried out by Monte Carlo simulation on the parameter sampling achieved by field measurement techniques in order to evaluate the influence of any possible small measurement errors on the data.

Sensitivity analysis showed that both ring and disc infiltrometer are tools reliable enough for the in situ measurements of field saturated hydraulic conductivity.

Finally, after a data merging procedure giving origin to different sets of data, the spatial correlation structure of field saturated hydraulic conductivity is investigated, using well-known geostatistical techniques.

\section{Introduction}

Research about water flow and pollutant transport processes in an unsaturated zone is one of the topic goals for hydro-geologists and soil scientists, because environmental protection and recovery depends on the possibility of forecasting the hydraulic behaviour of the subsoil.
HESSD

2, 1247-1298, 2005

Characterization of field saturated hydraulic conductivity

C. Fallico et al.

Title Page

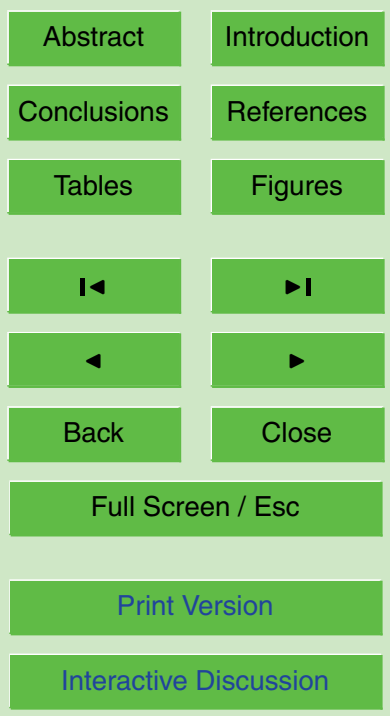

EGU 
Subsoil system modelling is currently supported by physically based mathematical models. The most reliable models in hydrogeology, among the different types of applicable models, are those characterized by spatially distributed parameters, because they are able to take into account the complex geometry and physical heterogeneity of 5 subsurface natural systems.

The practical use of this type of model, however, requires experimental measurements and the characterization of hydraulic properties, such as hydraulic conductivity, on the numerical mesh representing the subsurface system under analysis.

In unsaturated subsoil, hydraulic conductivity is a non-linear function of the matrix 10 potential and water content. In the opinion of many researches, the characterization of unsaturated zone based on the use of experimental acquisition of hydraulic conductivity data is a time-consuming and costly task, while data collection about water content and pressure head seems easier and quicker. Therefore, an inverse problem arose: how to achieve subsurface hydraulic parameter characterization by experimental sampling 15 prevalently of dependent variables, that is, soil moisture and matrix potential, rather than of hydraulic conductivity.

The modern approach to the inverse problem is based on the concept of effective parameters, which points out the problem of reducing the gap between the measurement scale and the model scale, in order to obtain the best possible reliable modelling issues.

To estimate the effective values of hydraulic conductivity two approaches were proposed in the scientific literature: the former based on up-scaling techniques (Bierkens et al., 2000; Khaleel et al., 2002), the latter based on optimisation techniques (Yeh and Zhang, 1996; Zhang and Yeh, 1997; Gupta et al., 1998).

25 In the context of studies aiming at effective parameter estimation by the optimisation approach, this paper tackles the problem of experimental data quality, referring to the large collection of water content, matrix potential, and hydraulic conductivity data, gathered at an experimental site equipped for unsaturated zone hydraulic monitoring in the alluvial basin of a Calabrian river, in the South of Italy. In particular, focusing attention

HESSD

2, 1247-1298, 2005

Characterization of field saturated hydraulic conductivity

C. Fallico et al.

\section{Title Page}

Abstract

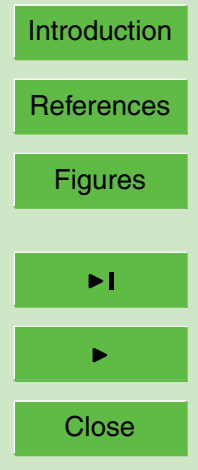

Back

Full Screen / Esc

Print Version

Interactive Discussion 
on field saturated hydraulic conductivity $K_{s}$, after some reminders about the measurement techniques used (ring infiltrometer, disc infiltrometer, laboratory tests), this work illustrates the results of data statistical analysis carried out in order to investigate the

effects of the different techniques of measurement on the geovariance of $K_{s}$. Sensitivity

5 analysis was then carried out by Monte Carlo simulation on disc and ring infiltrometer data in order to evaluate the influence of eventual small measurement errors on the data obtained.

Finally, after a data-merging procedure giving origin to different sets of data, the spatial correlation structure of $K_{s}$ is investigated, using well-known geostatistical tech10 niques.

\section{Methods}

2.1. Water movement in the unsaturated zone

In unsaturated porous media water flow is described by Richards's equation, derived by combining the Darcy-Buckingham equation with mass balance principle. The 1dimensional Richards's equation is written as follows:

$C(h) \frac{\partial h}{\partial t}=\frac{\partial}{\partial z}\left[k(h) \cdot \frac{\partial h}{\partial z}\right]+\frac{\partial k(h)}{\partial z}$

with

$C(h)=\frac{\partial \vartheta}{\partial h}$

where $h[L]$ is the soil water head, $\vartheta\left[L^{3} L^{-3}\right]$ is the volumetric water content, $z[L]$ is the distance of water vertical path, $t[T]$ is time, $K(h)\left[L T^{-1}\right]$ is the unsaturated hydraulic conductivity, $C(h)$ is the soil water capacity $\left[L^{-1}\right]$ (Richards, 1931).

Characterization of field saturated hydraulic conductivity

C. Fallico et al.

Title Page

Abstract

Conclusions

Tables

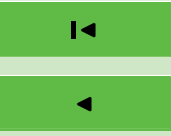

Back
Introduction

References

Figures

- I

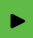

Close

Full Screen / Esc

Print Version

Interactive Discussion 
The hydraulic behaviour of unsaturated soils is characterized by soil hydraulic functions such as: the soil water retention curve $\vartheta(h)$, and the hydraulic conductivity curve $K(h)$ or $K(\vartheta)$.

\subsection{Measurement techniques}

5 The hydraulic properties of unsaturated soil can be experimentally defined both by in situ or laboratory measurement methods.

Among the several field techniques used to measure the hydraulic properties of soils in the unsaturated zone, infiltration-based methods showed viability and effectiveness more than others. In particular, with respect to the data of concern in this work, two tools were used: a single ring pressure infiltrometer (Vauclin et al., 1994; Mertens et al., 2002) and a tension disc infiltrometer (Perroux and White, 1988). Both tools allow the estimation of field saturated hydraulic conductivity $K_{s}$. Because of entrapped air during the infiltration process, field saturated hydraulic conductivity could be lower than hydraulic conductivity in completely saturated conditions. Thereby, $K_{s}$ will be referred

\subsubsection{Single ring pressure infiltrometer measurements}

The ring infiltrometer allows the estimation of the matric flux potential $\phi_{m}$ :

$\phi_{m}=\int_{h_{i}}^{0} K(h) d h$,

where $h_{i} \leq 0$ is the initial value of soil water head (Elrick and Reynolds, 1989).

HESSD

2, 1247-1298, 2005

Characterization of field saturated hydraulic conductivity

C. Fallico et al.

Title Page
Abstract

Conclusions

Tables

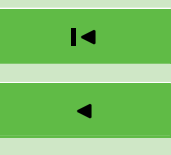

Back
Introduction

References

Figures

$\rightarrow 1$

Close
Full Screen / Esc

Print Version

$\alpha_{m}=\frac{K_{f s}}{\phi_{m}}$,

which provides a measure of the relative contributions of gravity and capillary forces to water movement in an unsaturated soil. 
According to steady-flow conditions, flow rate out of a ring infiltrometer is given by:

HESSD

$Q_{P I}=K_{f s}+\frac{H}{\pi \cdot r_{d} G} K_{f s}+\frac{\phi_{m}}{\pi \cdot r_{d} G}$,

2, 1247-1298, 2005

where $H[L]$ is the steady value of hydraulic head applied during the measurement, $G$ is a shape parameter given by

$G=0,316 \frac{d_{r}}{r_{d}}+0,184$

and $r_{d}[L]$ is the ring radius, $d_{r}$ is the depth of insertion of the ring into the soil (Reynolds and Elrick, 1990).

According to the Simultaneous Equation Approach (S.E.A.), two values of head $\left(H_{1}\right.$ and $\mathrm{H}_{2}$ ) were applied successively, in order to obtain the system of two equations from which the two unknown parameters $K_{f s}$ and $\phi_{m}$ (or $\left.\alpha_{m}\right)$ can be determined.

For an effective interpretation of ring infiltrometer measurements, some warnings should be considered. In the first place, it is important to underline that $K_{s}$ and $\alpha_{m}$ are calculated by the observed infiltration rates $\left(Q_{1}\right.$ and $\left.Q_{2}\left[L T^{-1}\right]\right)$, which correspond to the applied heads $\left(H_{1}\right.$ and $\left.H_{2}\right)$, and that $K_{s}$ and $\alpha_{m}$ are strongly dependent on the ratio ${ }_{5} Q_{2} / Q_{1}$ (Philip, 1985).

$Q_{2} / Q_{1}$ ratio can be affected by different source of error: a) Non-attainment of true steady state flow; b) Error in the experimental measurements of $Q_{1}$ and $Q_{2}$ because of air bubble size and reading errors in the permeameter; c) Entrapment of air in the soil due to water redistribution during filling of the permeameters and restarting of infiltration 20 (Heinen and Raats, 1990; Wu et al., 1993; Russo et al., 1997; Elrick and Reynolds, 1992).

The accuracy of measurements by single ring pressure infiltrometer can be affected by other factors: during the insertion of the infiltrometer ring, soil macrostructure can collapse for soil matrix compression (or soil shattering), and the wall of the ring can cut off non-vertical pores.

Characterization of field saturated hydraulic conductivity

C. Fallico et al.

Title Page
Abstract

Conclusions

Tables

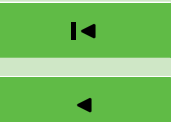

Back
Introduction

References

Figures

$\rightarrow$

$\checkmark$

Close
Full Screen / Esc

Print Version

Interactive Discussion 
For the tension disk infiltrometer the tension flux potential $\left(\phi_{t}\right)$ is given by:

2, 1247-1298, 2005

$\phi_{t}=\int_{\psi_{i}}^{\psi_{t}} K(\psi) d \psi$

with

$5 \quad \psi_{i}<<\psi_{t} \leq 0$,

Characterization of field saturated hydraulic conductivity

where $\psi_{t}$ is the constant water potential applied on the soil surface (Elrick and Reynolds, 1992).

Likewise for the ring infiltrometer, it is possible to define the parameter $\alpha_{m t}$, given by:

$\alpha_{t}=\frac{K_{t s}}{\phi_{t}}$

10 The interpretation of disc infiltrometer measurements is also based on an S.E.A.; according to the Wooding algebraic approximation of steady-state unconfined infiltration rate into soil from a circular source of radius $r$ (Wooding, 1968), the following relation was used (Angulo-Jaramillo et al., 2000):

$Q_{T l}=\pi \cdot r^{2} K_{t s} e^{\alpha \psi_{t}}\left[1+\frac{4}{\pi \cdot r \alpha_{t}}\right]$

15 Also for disc infiltrometer measurement interpretation some warnings should be taken in account. $K_{t s}$-values obtained by such a measuring device can be affected by errors and the accuracy of data depends on several critical factors (Elrick and Reynolds, 1992; Ankeny et al., 1991).

C. Fallico et al.

Title Page

Abstract

Introduction

Conclusions

References

Tables

Figures

14

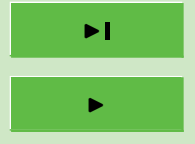

Back

Close

Full Screen / Esc

Print Version

Interactive Discussion 
Regarding the laboratory measurements method, having taken a number of undisturbed soil samples, the saturated hydraulic conductivity $\left(K_{s}\right)$ for each of them can be easily determined using a constant head permeameter (Klute, 1986). Of course, 5 the most critical constraint of laboratory measurement procedures is the condition of undisturbed sampling, which actually is very difficult to achieve.

\subsection{Statistical analysis}

Hereinafter the symbol $K_{s}$ will be used to indicate both saturated hydraulic conductivity $K_{f s}$ and $K_{t s}$, measured respectively for ring infiltrometer or disc infiltrometer test; in the same manner the symbols $\phi_{m}$ and $\alpha_{m}$ will be used to indicate respectively the parameters $\phi_{m}, \phi_{t}$ and $g \alpha_{m}, \alpha_{t}$.

Descriptive conventional statistics of $K_{s}$ based on the available data are achieved in order to compare the results provided by the different measurement techniques applied. Univariate distribution can be tested, by calculating relative frequency histogram 15 and cumulative probability distribution. A comparison between $K_{s}$-values obtained in the same locations by different measurement techniques can be a help to focus the advantages and limits of each measuring approach.

\subsection{Monte Carlo based sensitivity analysis}

Based on Monte Carlo techniques of numerical random generation it is possible to carry out a simple but effective error analysis of $K_{s}$ and $\alpha_{m}$ data collected by using ring and disc infiltrometers. The aim of such an error analysis is to assess the propagation of small random error in evaluating the steady-state inflow rates on the data acquisition of $K_{s}$ and $\alpha_{m}$. The error is assumed equivalent to a possible reading-off error on the reservoir of the measurement tools. The hypothesis of a normal distribution characterized by mean $0 \mathrm{~mm}$ and standard deviation equal to $1 \mathrm{~mm}$ is assumed. A number

Characterization of field saturated hydraulic conductivity

C. Fallico et al.

Title Page
Abstract

Conclusions

Tables

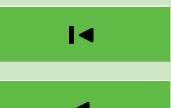

$\triangleleft$

Back
Introduction

References

Figures

$\rightarrow$

$\checkmark$

Close
Full Screen / Esc

Print Version

Interactive Discussion 
of 1000 Monte Carlo simulations of reading errors is performed for each measurement location. The error is then added to read-off values and $K_{s}$ and $\alpha_{m}$ re-calculated using the SEA for each random error. Finally, considered the mean value $\mu$ and standard HESSD deviation $\sigma$ of $K_{s}$ and $\alpha_{m}$ in each measurement location, a diagram $\mu-\sigma$ both for $K_{s}$ 5 and $\alpha_{m}$. The trend and scattering of standard deviation can be therefore evaluated in order to obtain conclusions about $K_{s}$ and $\alpha_{m}$ sensitivity to small measurement errors (Saltelli et al., 2000).

\subsection{Geostatistical analysis}

The spatial correlation structure of $\mathrm{K}_{s}$ in the unsaturated zone is investigated applying geostatistical techniques such as the calculation based on the available data of a few points of the semivariogram function, which, with respect to a generic variable $Z$ spatially distributed, is given by

$\gamma\left(h_{l}\right)=\frac{1}{2 n\left(h_{l}\right)} \sum_{i=1}^{n\left(h_{l}\right.}\left[z\left(x_{i}\right)-z\left(x_{i}+h_{l}\right)\right]^{2}$,

where $\gamma\left(h_{l}\right)$ is the estimated semivariance for lag distances class $h_{l}, z\left(x_{i}\right)$ and $z\left(x_{i}+h_{l}\right)$ are the measured sample values at point $x_{i}$ and $x_{i}+h_{l}$ respectively, and $n\left(h_{l}\right)$ is the

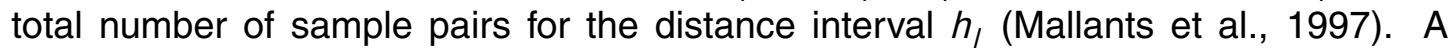
variogram model is then searched in order to fit the experimental points (Goovaerts, 1997).

Characterization of field saturated hydraulic conductivity

C. Fallico et al.

Title Page

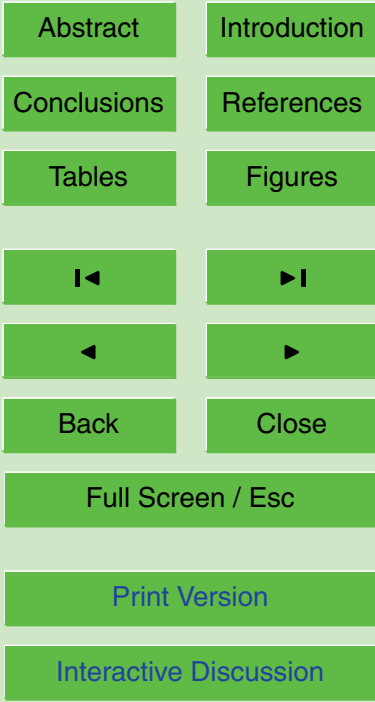




\section{Characterization of the field saturated hydraulic conductivity on a hill slope: materials}

3.1. The experimental site: hydrogeological settings and measurement locations

The experimental site, located in Calabria (South Italy), in the basin of the Turbolo 5 river, the left affluent of the Crati river, is a flat alluvial area with a surface of $2800 \mathrm{~m}^{2}$ $(70 \mathrm{~m} \times 40 \mathrm{~m})$ and a mean slope of about $6 \%$ (Figs. 1a and $1 \mathrm{~b}$ ). Thanks to the collaboration between the Institute for Land and Water Management of the Katholieke Universiteit of Leuven (Belgium) and the Department of Soil Conservation of the University of Calabria (Italy) it was equipped for monitoring the soil water content $(\theta)$ at different depths and assessing other precipitation and runoff processes; moreover, measurements of pressure heads were performed, using special devices and probes (TDR, tensiometers, gutters, etc). Figure 2 shows a view the experimental site.

The aim of this work, however, is the characterization of field saturated hydraulic conductivity; therefore, hereinafter, just the $K_{s}$-data collected in a restricted zone $15(40 \mathrm{~m} \times 20 \mathrm{~m})$ of the whole experimental site will be dealt with. No other mention will be made to the other data collected.

Geological settings of the area include alluvial deposits with prevalence of sand and conglomerates and a widespread presence of loam. The shallow aquifer is located at $8.3 \mathrm{~m}$ from the ground surface with a thickness of about $8 \mathrm{~m}$.

20 Soon after the summer of $2002 K_{s}$-measurements began, 30 of which were carried out by single ring infiltrometer and 30 by disc infiltrometer. In addition 30 undisturbed soil samples were taken in the same locations of single ring infiltrometer measurement. Figure 3 shows in situ measurement locations and undisturbed soil sampling points.

The choice of the measurement period was not casual. In fact, Eqs. (3) and (7) show 25 that the flux potential is a function of the initial soil water head. Then the measurement process of $K_{s}$ could be affected by the initial moisture conditions of the site. Dependence of flux potential on the initial soil water head, however, can be neglected if the initial soil water head is very negative, that is, in other words, if the initial soil is dry

Characterization of field saturated hydraulic conductivity

C. Fallico et al.

Title Page

Abstract

Conclusions

Tables

14

4

Back

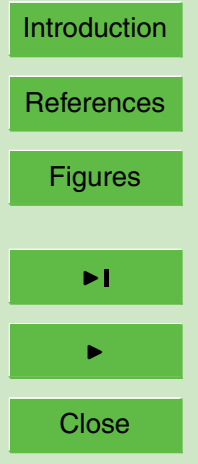

Full Screen / Esc

Print Version

Interactive Discussion 
(Bagarello and Provenza, 1996; Russo et al., 1997).

For this reason, the single ring pressure infiltrometer measurements were carried out after a long dry period. Five data of $K_{s}$ and $\alpha_{m}$ obtained by single ring pressure infiltrometer were discarded because they showed negative values. In the same manner, 5 two anomalous values determined in laboratory were cut off from the data set. On the contrary, no negative values was provided by the tension disc infiltrometer measurements.

\subsection{Results and discussion}

\subsubsection{Statistical analysis of data}

In order from a statistical point of view to characterize each data set, derived by using different measuring techniques, some univariate statistics, such as mean value, standard deviation and asymmetry, were considered; in particular the asymmetry was calculated by the Pearson coefficient. Table 1 and Fig. 4 summarize and compare statistics obtained for each data source. A log scale needs to be used to keep together 15 the resulting variety of magnitude orders in the same diagram (Jury, 1985; Zavattaro et al., 1999; Mohanty et al., 1994; Jacques, 2000). Figures 5a and 5b, 6a and 6b, 7a and $7 \mathrm{~b}$, report the relative frequency histogram for each data set, both on the natural and on the logarithmic scale. Figures $5 c$ and $5 d, 6 c$ and $6 d, 7 c$ and $7 d$, report the probability plot for each data set, both on the natural and on the logarithmic scale.

From the above-mentioned figures the following elements can be observed: a) The disc infiltrometer provides data ranging from about 50 to about $600 \mathrm{~cm} /$ day, enough homogeneous but asymmetric with respect to the mean value; b) The ring infiltrometer provides data ranging from about 100 to about $37000 \mathrm{~cm} /$ day, very spread and enough symmetric with respect to the mean value; c) The laboratory provides data ranging 25 from about 1 to $22000 \mathrm{~cm} /$ day, very spread and asymmetric with respect to the mean value.

Such a statistical comparison of $K_{s}$ data obtained with different measurement tech-

HESSD

2, 1247-1298, 2005

Characterization of field saturated hydraulic conductivity

C. Fallico et al.

Title Page

Abstract Introduction

Conclusions References

Tables Figures

14

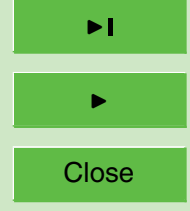

Full Screen / Esc

Print Version

Interactive Discussion 
niques provides results which are coherent with the conclusions of other studies on the $K_{s}$ estimate problem (Herman et al., 2003).

The logarithmic transformation of data, however, corrects the asymmetry of the disc infiltrometer data, and produces a distribution less spread and asymmetric for the ring

5 infiltrometer data. For the lab data set, on the contrary, the asymmetry is reduced but the standard deviation remains high. In addition, lab data distribution seems tri-modal. In fact, for disc and ring infiltrometer data the asymmetry is due to few outliers, much lower or higher than the data trend. On the contrary, the lab data set seems originated by three different data sources, rather than by a trend component plus few outliers.

\subsubsection{Comparison of ring infiltrometer and laboratory data}

A specific comparison was made between ring infiltrometer and lab data, because measurements were achieved in the same locations (Reynolds et al., 2000). The comparison was possible in 22 locations. Figures $8 \mathrm{a}$ and $8 \mathrm{~b}$ represent the results of such a comparison. Ring infiltrometer measurements, except for two locations, show values much higher than lab data, which, in many cases, appear very low.

Taken the two $K_{s}$-values recorded in a fixed location respectively by ring infiltrometer and laboratory measurement method, the ratio between the lowest value and the highest one provides a likelihood index $\left(L_{i}\right)$, which can be used to compare the order of magnitude of ring infiltrometer data versus the laboratory ones.

20 Figures $9 \mathrm{a}$ and $9 \mathrm{~b}$ report such a likelihood index $L_{i}$, pointing out that: a) ring infiltrometer data and laboratory data show the same order of magnitude just in seven cases; b) the lowest values of $L_{i}$ occur prevalently for low values of lab $K_{s}$-data.

\subsubsection{Sensitivity analysis of disc and ring infiltrometer data}

Sensitivity analysis was carried out separately on ring and disc infiltrometer data by using Monte Carlo simulations to generate the random errors affecting the reading of levels recorded by the reservoirs of the measurement tools. Figures $10 \mathrm{a}$ and $10 \mathrm{~b}$

HESSD

2, 1247-1298, 2005

Characterization of field saturated hydraulic conductivity

C. Fallico et al.

Title Page

Abstract Introduction

Conclusions

Tables References Figures

14

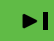

4

Back

Close

Full Screen / Esc

Print Version

Interactive Discussion 
represent the results of sensitivity analysis for ring infiltrometer measurements. Figures $11 \mathrm{a}$ and $11 \mathrm{~b}$ represent the results for disc infiltrometer measurements. The scatter-diagrams in the above mentioned figures represent the standard deviation versus mean values of $K_{s}$, and $\alpha_{m}$.

5 The statistical elaboration of Monte Carlo simulations show that: a) Small random errors made during the test management affect the ring infiltrometer measurement of the hydraulic conductivity less than the disc infiltrometer measurement of $K_{s}$; in fact, the standard deviation of the former is lower for an order of magnitude than the standard deviation of the latter. Both ring and disc infiltrometer measurements, however, o show standard deviation distributions without specific trend and more or less accumulated around low values; b) Concerning $\alpha_{m}$ measurement, standard deviation vs mean values graphics, represented on the logarithmic scale, show, on the contrary, that the ring infiltrometer is more sensitive to small random measurement errors than the disc infiltrometer. In addition, the standard deviation of $\alpha_{m}$ in the case of the ring infiltrom15 eter is characterized by an increasing drift which is absent for the disc infiltrometer measurements.

\subsubsection{Geostatistical analysis}

\section{a) Data merging}

Eight data sets were created by merging the disc infiltrometer $K_{s}$-measurements with variable increasing portions of $K_{s}$-data, deduced from laboratory tests or ring infiltrometer measurements, as explained hereinafter. Four data sets include disc tension infiltrometer and laboratory data; the remaining four data sets include disc tension infiltrometer and ring pressure infiltrometer data.

These data sets were built following the criteria illustrated in Table 2. The likelihood

\section{HESSD}

2, 1247-1298, 2005

Characterization of field saturated hydraulic conductivity

C. Fallico et al.

\section{Title Page}

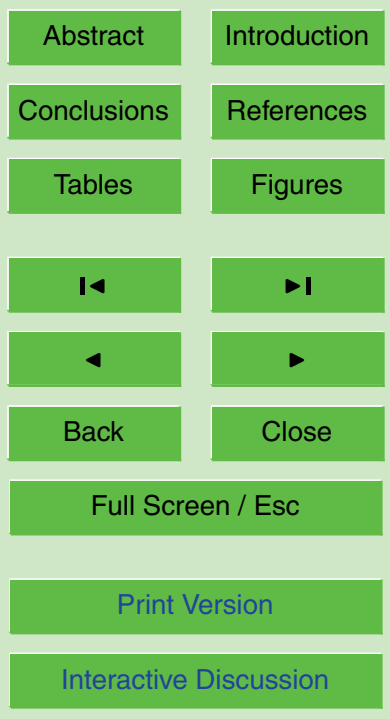

EGU 
ing all the disc infiltrometer data with different portions of the laboratory data, which was defined according to assigned values of $L_{i}$, as shown in Table 2. It should be observed that the fourth data set is constituted of all the available data collected both by the disc infiltrometer and the laboratory test. In the same manner the four data sets labelled as

5 "discring" were obtained by joining all the disc infiltrometer data with variable quotas of the ring infiltrometer data (see Table 2); also in this case the fourth data set contains all the available data obtained both by the disc and the ring infiltrometer. Table 2 also shows the total number of data considered for each data set.

b) Spatial correlation structure analysis

10 Using each of the above mentioned data sets, the spatial correlation structure of $K_{s}$ in the experimental site considered was investigated.

Figure 12 summarizes the experimental variograms obtained for the data sets formed by the disc infiltrometer data plus increasing portions of laboratory data. Figure 13 shows the experimental variograms obtained for the data sets formed by the disc infiltrometer data plus increasing portions of the ring infiltrometer data. Figure 12 points out a non-stationary behaviour for $K_{s}$. Figure 13, on the contrary, shows that the nonstationary behaviour of $K_{s}$ is confirmed just for the data set labelled as "discring1", while for the other ones the behaviour of $K_{s}$ gradually trends to become stationary, with the achievement of a well-defined sill.

Hence, as was expected, the results of spatial correlation analysis are similar if the laboratory and ring infiltrometer data with high $L_{i}$ (disclab1 variogram vs discring1 variogram) are added to the disc infiltrometer data.

On the contrary, the variograms show very different spatial structure for the data sets involving the laboratory and ring infiltrometer data with low $L_{i}$.

Figures $14 a, 14 b$ and $15 a, 15 b$ show variogram models which were selected for the above-mentioned data sets. The aim was to compare the spatial structure of $K_{s}$-data according to the variation of $L_{i}$, that is, to investigate how $K_{s}$-data spatial structure changes when data with decreasing $L_{i}$ are involved in the analysis.

As expected for the lowest values of $L_{i}$ the spatial structure of $K_{s}$-data is very different

HESSD

2, 1247-1298, 2005

Characterization of field saturated hydraulic conductivity

C. Fallico et al.

\section{Title Page}

\section{Abstract}

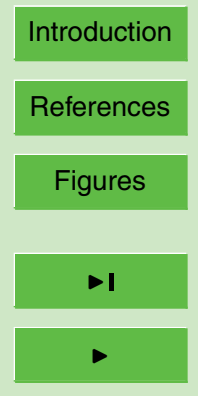

4

Conclusions

Tables

14

Back

Close

Full Screen / Esc

Print Version

Interactive Discussion 
if the data sets labelled as "disclab" are considered instead of the data sets labelled as "discring".

Figures $15 \mathrm{a}$ and $15 \mathrm{~b}$ show how a non-stationary model should be always assumed for the "disclab" data sets while a stationary model can be adopted for the "discring" 5 data sets when the portion of the ring infiltrometer data increases, that is, when $L_{i}$ decreases.

\section{Conclusions}

The present paper, referring to the field saturated hydraulic conductivity measurements performed in an experimental site purposely equipped in the unsaturated zone of the

10 Turbolo basin (Calabria, Italy), faced the problem of data quality achieved either by laboratory analysis, on undisturbed samples, or by field devices (tension disc infiltrometer and pressure ring infiltrometer).

Statistical analysis of $K_{s}$ data showed that the measurements performed by the tension disc infiltrometer supplied $K_{s}$-values which are on average lower and more homo15 geneous than other ones; moreover, the starting asymmetry of the data set is effectively corrected by a simple logarithmic transformation. Data acquired by the pressure ring infiltrometer and those acquired in the laboratory, on the contrary, are characterized by a marked asymmetry and by a high scattering around the mean value, as well as by several outliers, much higher or much lower than the mean value.

20 Specifically, the laboratory data seem to be formed by three data subsets which are mutually uncorrelated, above all because of the high influence of very low hydraulic conductivity values. So much so that the logarithmic transformation, when applied to $K_{s}$-values obtained by pressure ring infiltrometer, is able to lead the behaviour of data again to a gaussian scheme, while, when applied to the laboratory data, it produces a 3-modal distribution.

Comparison of the data obtained in the same locations, by pressure ring infiltrometer and by laboratory analysis, showed that about $1 / 3$ of the data has the same order of

HESSD

2, 1247-1298, 2005

Characterization of field saturated hydraulic conductivity

C. Fallico et al.

Title Page

Abstract Introduction

Conclusions References

Tables Figures

14

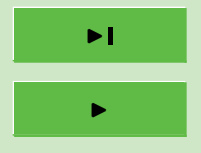

4

Back

Close

Full Screen / Esc

Print Version

Interactive Discussion 
magnitude and that the highest differences occurs in correspondence to the lowest laboratory data.

Sensitivity analysis, carried out on $K_{s}$-field data, using Monte Carlo simulations, showed that the pressure ring infiltrometer is a tool reliable enough for the in situ de5 termination of $K_{f s}$, while it does not produce such stable data for the parameter $\alpha_{m}$.

The measurements performed by tension disc infiltrometer show, on the contrary, a reliable enough level for the in situ estimation either of $K_{t s}$, or $\alpha_{m}$.

Geostatistical analysis, performed on data sets obtained joining the tension disc infiltrometer data with progressively increasing portions of the data gathered respectively 10 by laboratory analysis and by pressure ring infiltrometer, showed that: a) the addition of laboratory data produces variograms with non-stationary behaviour, which is confirmed whatever is the entity of the data set analyzed every time; b) the addition of pressure ring infiltrometer data produces variograms which, starting from a non-stationary state, gradually behave like stationary spherical functions, characterized by a very small correlation scale (about $5 \div 6 \mathrm{~m}$ ).

The results of $K_{s}$-spatial analysis, obtained by merging and analyzing only in situ sampling data, are similar to those which can be found in analogous studies referred to in the literature; on the contrary, the results obtained by analyzing data sets which were formed both by field and laboratory data show a non-stationary behaviour which cannot be ascribed to the physical presence of a drift component. Therefore, it could be due to the more irregular composition of the laboratory data.

Acknowledgements. The authors thank the J. Feyen, Director of the Institute for Land and Water Management of the Katholieke Universiteit Leuven (Belgium), for his precious suggestions and to have allowed this research, furnishing the measurement devices and performing the 25 laboratory tests; furthermore they thank, also, the J. Mertens, Research Hydrologist of Lincoln Environmental Ruakura Research Centre (Hamilton, New Zealand), that participated to the initial stage of the research.

HESSD

2, 1247-1298, 2005

Characterization of field saturated hydraulic conductivity

C. Fallico et al.

Title Page
Abstract

Conclusions

Tables

14

$\triangleleft$

Back
Introduction

References

Figures

$\rightarrow$

$\checkmark$

Close
Full Screen / Esc

Print Version

Interactive Discussion 


\section{References}

Angulo-Jaramillo, R., Vandervaere, J. P., Roulier, S., Thony, J. L., Gaudet, J. P., and Vauclin, M.: Field measurement of soil surface hydraulic properties by disc and ring infiltrometers. A review and recent developments, Soil and Tillage Research, 55, 1-29, 2000.

5 Ankeny, M.D., Ahmed, M., Kaspar, T. C. and Horton, R.: Simple field method for determining unsaturated hydraulic conductivity, Soil Sci. Soc. Am. J., 55, 467-470, 1991.

Bagarello, V. and Provenza, G.: Factors affecting field and laboratory measurements of saturated hydraulic conductivity, Trans. ASHE, 39, 153-159, 1996.

Bierkens, M. F. P., Finke, P. A., and De Willigen, P.: Upscaling and downscaling methods for environmental research. Developments in plant and soil sciences, Kluwer Academic Publishers, 88, 190 p., 2000.

Elrick, D. E. and Reynolds, W. D.: Infiltration from Constant-Head Well Permeameters and Infiltrometers, Advances in Measurement of Soil Physical Properties: Bringing Theory into Practice, SSSA Special Publication Number 30, 1-25, 1992.

15 Elrick, D. E., Reynolds, W. D., and Tan, K. A.: Hydraulic conductivity measurements in the unsaturated zone using improved well analyses, Groundwater Monit. Rev., 9, 184-193, 1989.

Goovaerts, P.: Geostatistics for Natural Resources Evaluation, Applied Geostatistics Series, A. G. Jurnel G. Ed., Oxford University Press, Inc., New York, 1997.

Gupta, V. K., Sorooshian, S., and Yapo, P. O.: Towards improved calibration of hydrological models: Multiple and non-commensurable measures of information, Water Resour. Res., 34, 751-763, 1998.

Jacques, D.: Analysis of water flow and solute transport at the field scale. Ph.D.-Thesis No. 454, Faculty of Agricultural and Applied Biological Sciences, K.U. Leuven (Belgium), 255 p., 2000.

Jury, W. A.: Spatial variability of soil physical parameters in solute migration: A critical literature review. EPRI EQ-4228 Project 2485-6, Riverside (CA, USA), 1985.

Heinen, M. and Raats, P. A. C.: Evaluation of two models describing the steady discharge from a constant head well permeameter into unsaturated soil, Soil Sci., 150, 401-412, 1990.

Herman, S., Mertens, J., Timmerman, A., and Feyen, J.: Comparison of tension infiltrometer, single-ring pressure infiltrometer and soil core $\mathrm{K}_{\text {sat }}$ estimates on a sandy loam hillslope, Proceedings of EGS-AGU-EUG Joint Assembly, Nice (France), 2003.

Khaleel, R., Yeh, T.-C. J., and Lu, Z.: Upscaled flow and transport properties for heterogeneous

\section{HESSD}

2, 1247-1298, 2005

Characterization of

field saturated

hydraulic

conductivity

C. Fallico et al.

Title Page

\section{Abstract}

Introduction

Conclusions

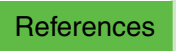

Tables

Figures

14

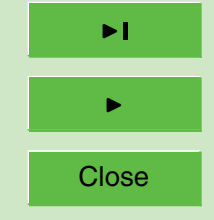

Back

Close

Full Screen / Esc

Print Version

Interactive Discussion 
unsaturated media, Water Resour. Res., 38, 5, doi:10.1029/2000WR000072, 2002.

Klute, A.: Water Retention: Laboratory Methods, in: Methods of Soil Analysis, Part 1. Physical and Mineralogical Methods, Second Edition, edited by: Klute, A., Agronomy, 9, 1986.

Mallants, D., Mohanty, B. P., Vervoort, A., and Feyen, J.: Spatial analysis of saturated hydraulic conductivity in a soil with macropores, Soil Techn., 10, 115-131, 1997.

Mertens, J., Jacques, D., Vanderborght, J., and Feyen, J.: Characterisation of the fieldsaturated hydraulic conductivity on a hillslope: In situ single ring pressure linfiltrometer measurements, J. Hydrol., 263, 217-229, 2002.

Mertens, J.: Parameter estimation strategies in unsaturated zone modelling. PhD-Thesis No. 583, Faculty of Agricultural and Applied Biological Sciences, K.U. Leuven (Belgium), 2003.

Mohanty, B. P., Ankeny, M. D., Horton, R., and Kanwar, R. S.: Spatial analysis of hydraulic conductivity using disc infiltrometers, Water Resour. Res., 30, 2489-2498, 1994.

Perroux, K. M. and White, I.: Designs for disc permeameters, Soil Sci. Soc. Am. J., 52, 12051215, 1988.

Philip, J. R.: Approximate analysis of the borehole permeameter in unsaturated soil, Water Resour. Res., 21, 1025-1033, 1985.

Reynolds, W. D. and Elrick, D. E.: Ponded infiltration from a single ring. Part. 1. Analysis of steady flow, Soil Sci. Soc. Am. J., 54, 1233-1241, 1990.

Reynolds, W. D., Bowman, B. T., Brunke, R. R, Drury, C. F., and Tan, C. S.: Comparison of tension infiltrometer, pressure infiltrometer and soil core estimates of saturated hydraulic conductivity, Soil Sci. Soc. Am. J., 64, 478-484, 2000.

Richards, L. A.: Capillary conduction of liquids through porous mediums, Physics, 1, 318-333, 1931.

Russo, D., Russo, I., and Laufer, A.: On the spatial variability of parameters of the unsaturated hydraulic conductivity, Water Resour. Res., 33, 947-956, 1997.

Saltelli, A., Chan, K., and Scott, E.M.: Sensitivity analysis. Wiley Series in Probability and Statistics, John Wiley and Sons, New York, 477 p., 2000.

Vauclin, M., Elrick, D. E., Thony, J. L., Vachaud, G., Revol, P., and Ruelle, P.: Hydraulic conductivity measurements of the spatial variability of a loamy soil, Soil Technol., 7, 181-195, 1994.

Wooding, R. A.: Steady infiltration from a shallow circular pond, Water Res., 4, 1259-1273, 1968.

Wu, L., Swan, J. B., Nieber, J. L., and Allmaras, R. R.: Soil-macropore and layer influences on
HESSD

2, 1247-1298, 2005

Characterization of

field saturated

hydraulic

conductivity

C. Fallico et al.

\section{Title Page}

Abstract

Introduction

Conclusions

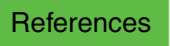

Tables

Figures

14

$\rightarrow$

4

Back

Close

Full Screen / Esc

Print Version

Interactive Discussion 
saturated hydraulic conductivity measured with borehole permeameters, Soil Sci. Soc. Am. J., 57, 917-923, 1993.

Yeh, T. C. J. and Zhang, J.: A geostatistical inverse method for variably saturated flow in the vadose zone, Water Resour. Res., 32, 2757-2766, 1996.

5 Zavattaro, L., Jarvis, N., and Persson, L.: Use of similar media scaling to characterise spatial dependence of near saturated hydraulic conductivity, Soil Sci. Soc. Am. J., 63, 486-492, 1999.

Zhang, J. and Yeh, T. C. J.: An iterative geostatistical inverse method for steady flow in the vadose zone, Water Resour. Res., 33, 63-71, 1997.

\section{HESSD}

2, 1247-1298, 2005

Characterization of field saturated hydraulic conductivity

C. Fallico et al.

Title Page

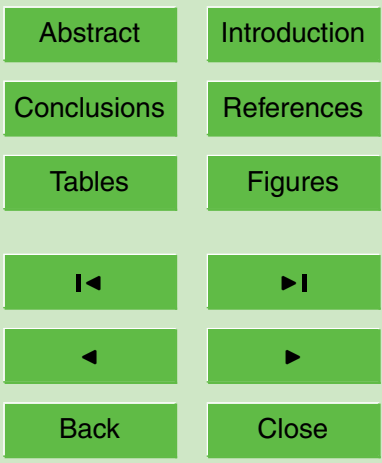

Full Screen / Esc

Print Version

Interactive Discussion 


\section{HESSD}

2, 1247-1298, 2005

Characterization of field saturated hydraulic conductivity

Table 1. Summary of data simple statistics.

C. Fallico et al.

\begin{tabular}{llll}
\hline Statistics & $\begin{array}{l}\text { Data }(\mathrm{cm} / \mathrm{s}) \\
\text { Disc infiltrometer }\end{array}$ & Ring infiltrometer & Laboratory \\
\hline Asymmetry & 2.5146 & 2.0834 & 3.2204 \\
Standard deviation & 0.0012 & 0.0996 & 0.0553 \\
Median value & 0.0018 & 0.0396 & 0.0008 \\
Mean value & 0.0022 & 0.0842 & 0.0236 \\
Minimum value & 0.0006 & 0.0015 & $1.743 \mathrm{E}-05$ \\
Maximum value & 0.0069 & 0.4256 & 0.2546 \\
\hline
\end{tabular}

Title Page

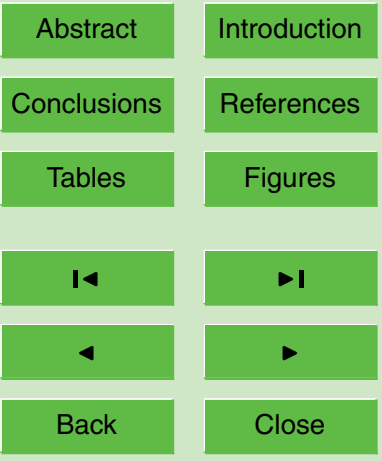

Full Screen / Esc

Print Version

Interactive Discussion 
Table 2. Data set composition.

\begin{tabular}{lll}
\hline Data set label & Merging criteria & $\begin{array}{l}\text { Total number } \\
\text { of data }\end{array}$ \\
\hline Disclab1 & Disc infiltrometer data + laboratory data for which $L_{i} \geq 10^{-1}$ & 37 \\
Disclab2 & Disc infiltrometer data + laboratory data for which $L_{i} \geq 10^{-2}$ & 43 \\
Disclab3 & Disc infiltrometer data + laboratory data for which $L_{i} \geq 10^{-4}$ & 52 \\
Disclab & Disc data + all laboratory data & 58 \\
Discring1 & Disc data + ring infiltrometer data for which $L_{i} \geq 10^{-1}$ & 37 \\
Discring2 & Disc data + ring infiltrometer data for which $L_{i} \geq 10^{-2}$ & 43 \\
Discring3 & Disc data + ring infiltrometer data for which $L_{i} \geq 10^{-4}$ & 52 \\
Discring & Disc data + all ring infiltrometer data & 55 \\
\hline
\end{tabular}

\section{Characterization of field saturated hydraulic conductivity}

C. Fallico et al.

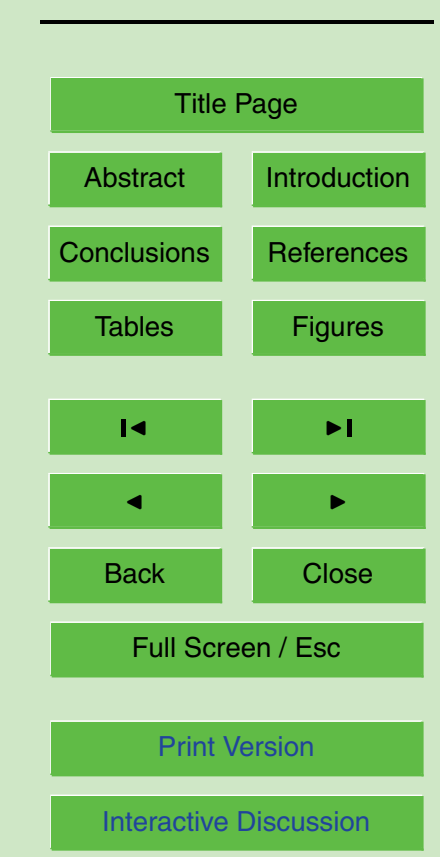

EGU 


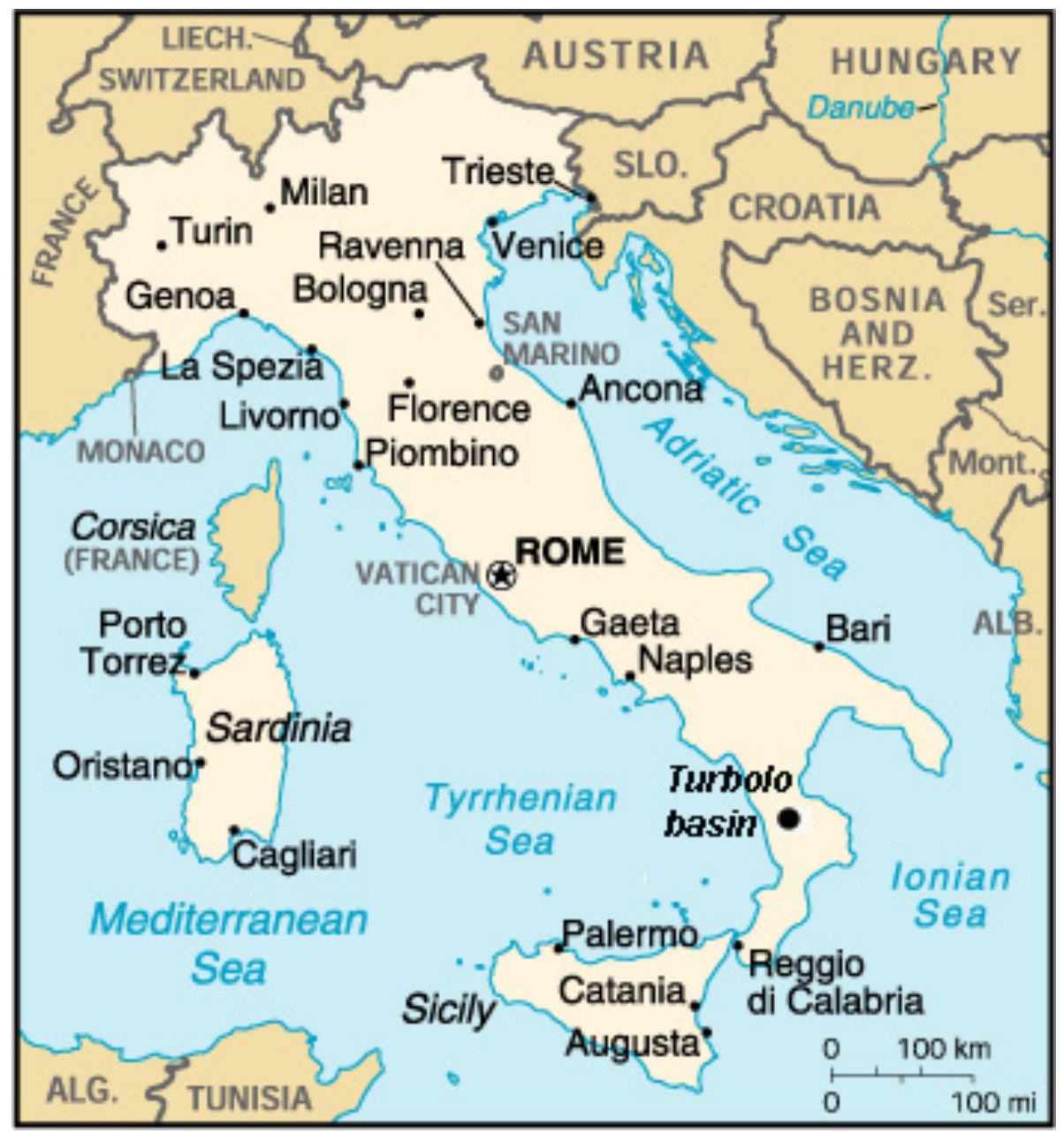

HESSD

2, 1247-1298, 2005

\section{Characterization of field saturated hydraulic conductivity \\ C. Fallico et al.}

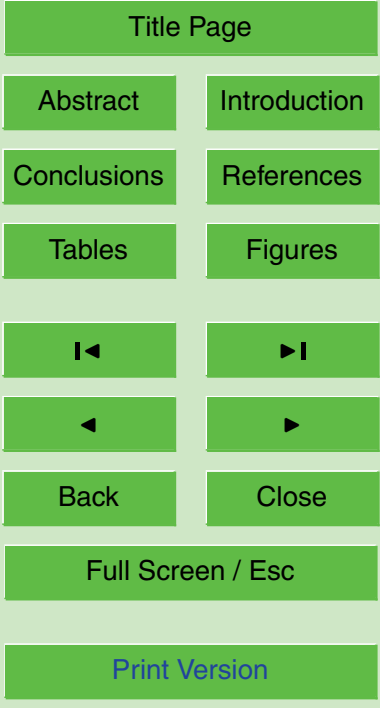

Interactive Discussion

Fig. 1. (a) Geographical location of Turbolo basin. 


\section{HESSD}

2, 1247-1298, 2005

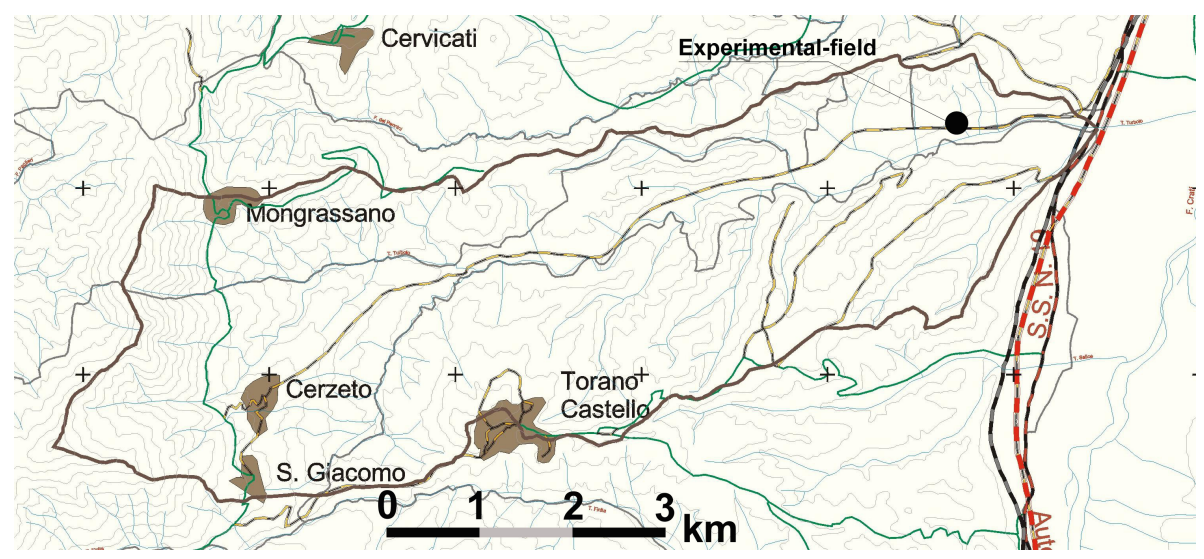

\section{Characterization of field saturated hydraulic conductivity \\ C. Fallico et al.}

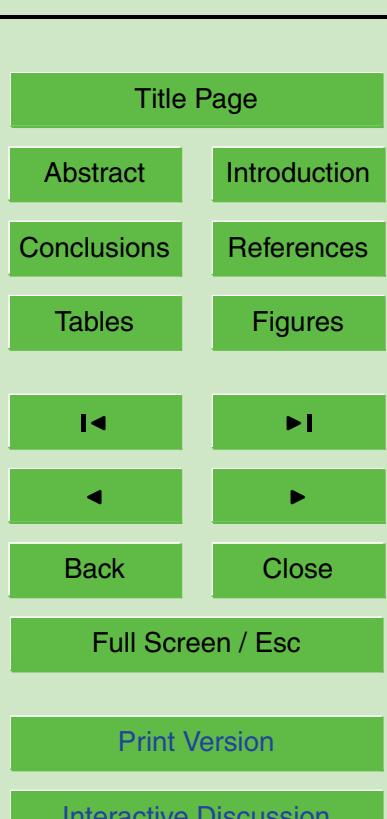

Interactive Discussion 


\section{HESSD}

2, 1247-1298, 2005

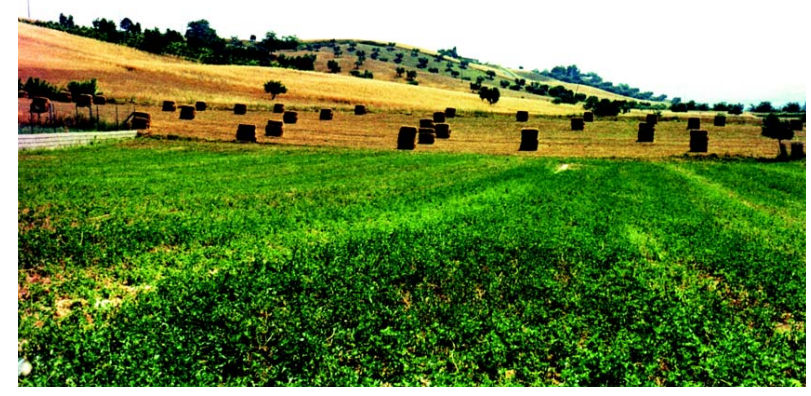

\section{Characterization of field saturated hydraulic conductivity \\ C. Fallico et al.}

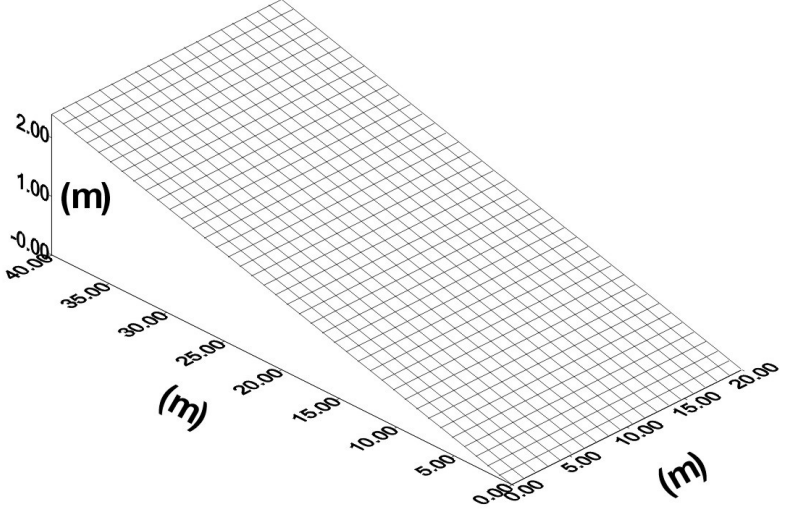

Title Page

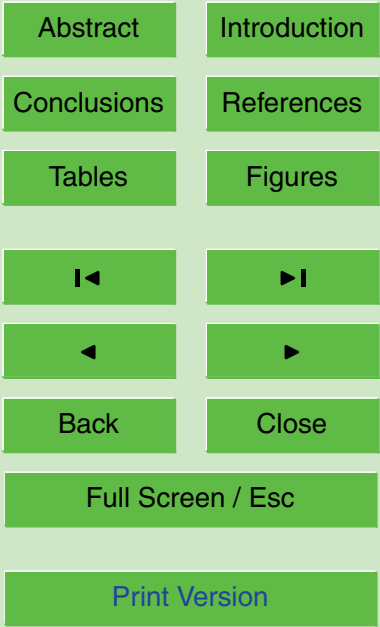

Fig. 2. View of the experimental site. 


\section{HESSD}

2, 1247-1298, 2005

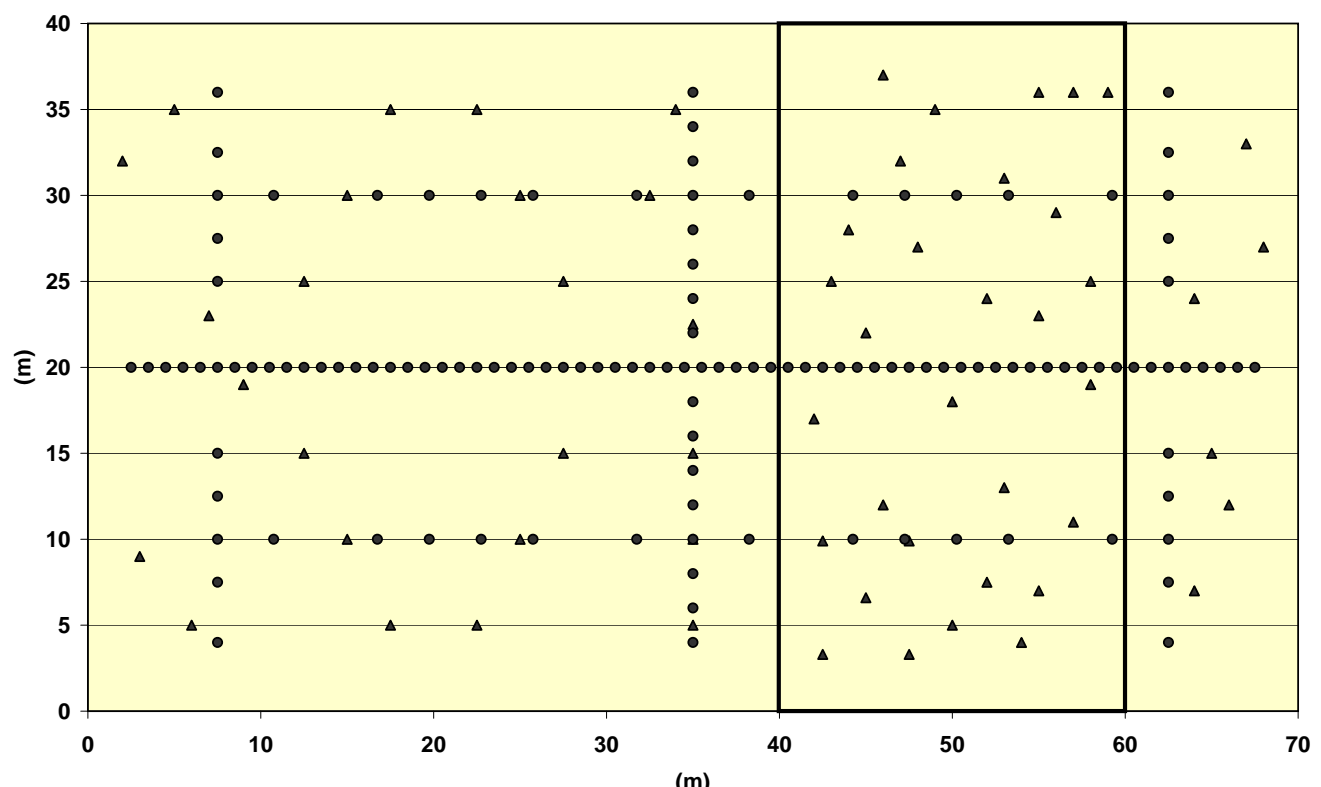

(m)

Characterization of field saturated hydraulic conductivity

C. Fallico et al.

\section{Title Page}

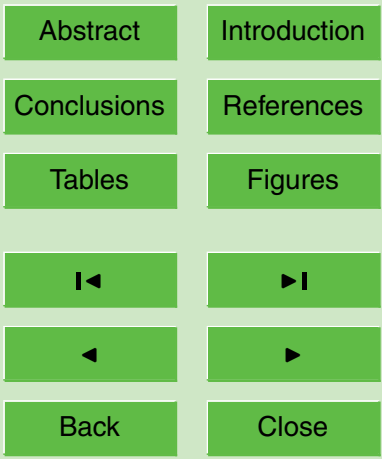

Fig. 3. Measurement locations. • Tension disc infiltrometer measurement locations. $\Delta$ Pressure ring infiltrometer measurement locations and undisturbed soil sampling points.

Full Screen / Esc

Print Version

Interactive Discussion 


\section{HESSD}

2, 1247-1298, 2005

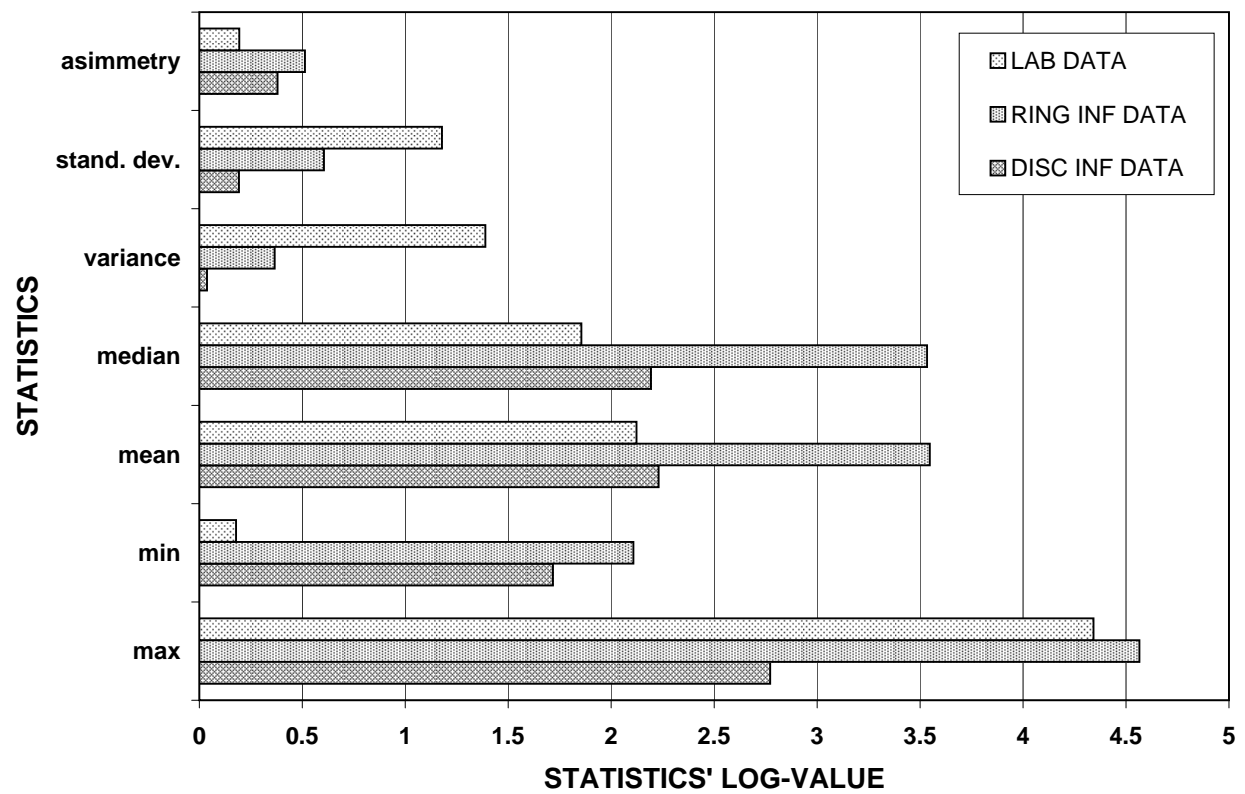

Characterization of field saturated hydraulic conductivity

C. Fallico et al.

Title Page

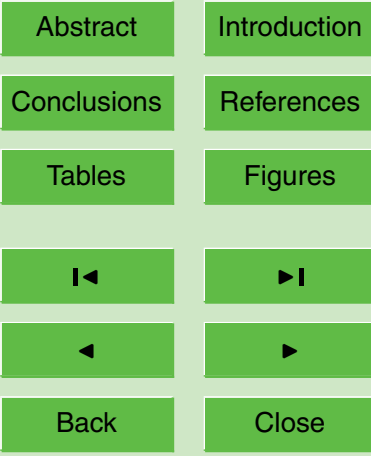

Fig. 4. Comparison of $K_{s}$-data main statistics.

\section{Full Screen / Esc}

Print Version

Interactive Discussion 


\section{HESSD}

2, 1247-1298, 2005

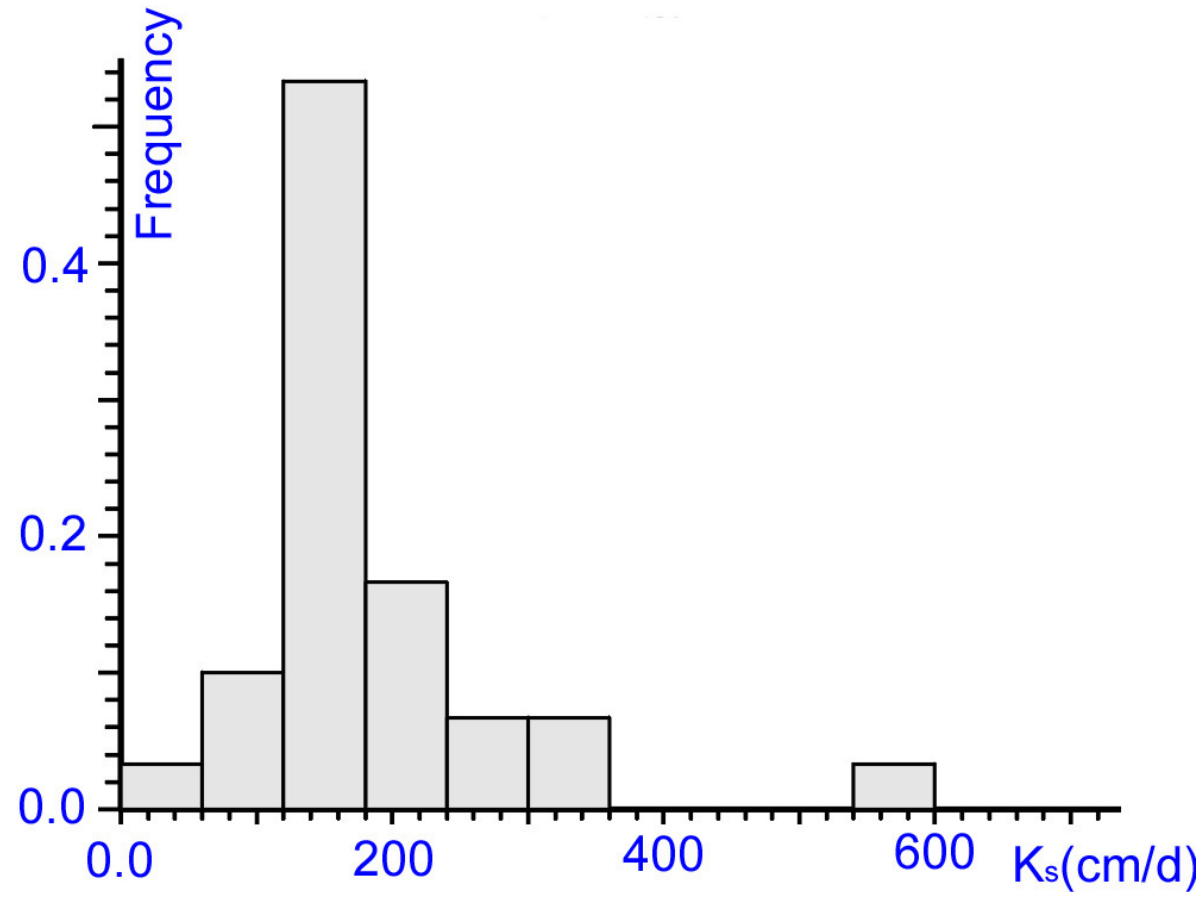

Characterization of field saturated hydraulic conductivity

C. Fallico et al.

Title Page

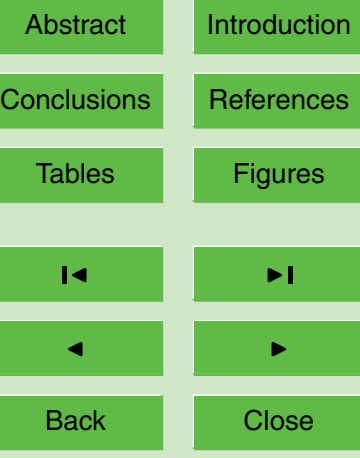

Full Screen / Esc

Fig. 5. (a) Disc infiltrometer data histogram.

Print Version

Interactive Discussion 


\section{HESSD}

2, 1247-1298, 2005

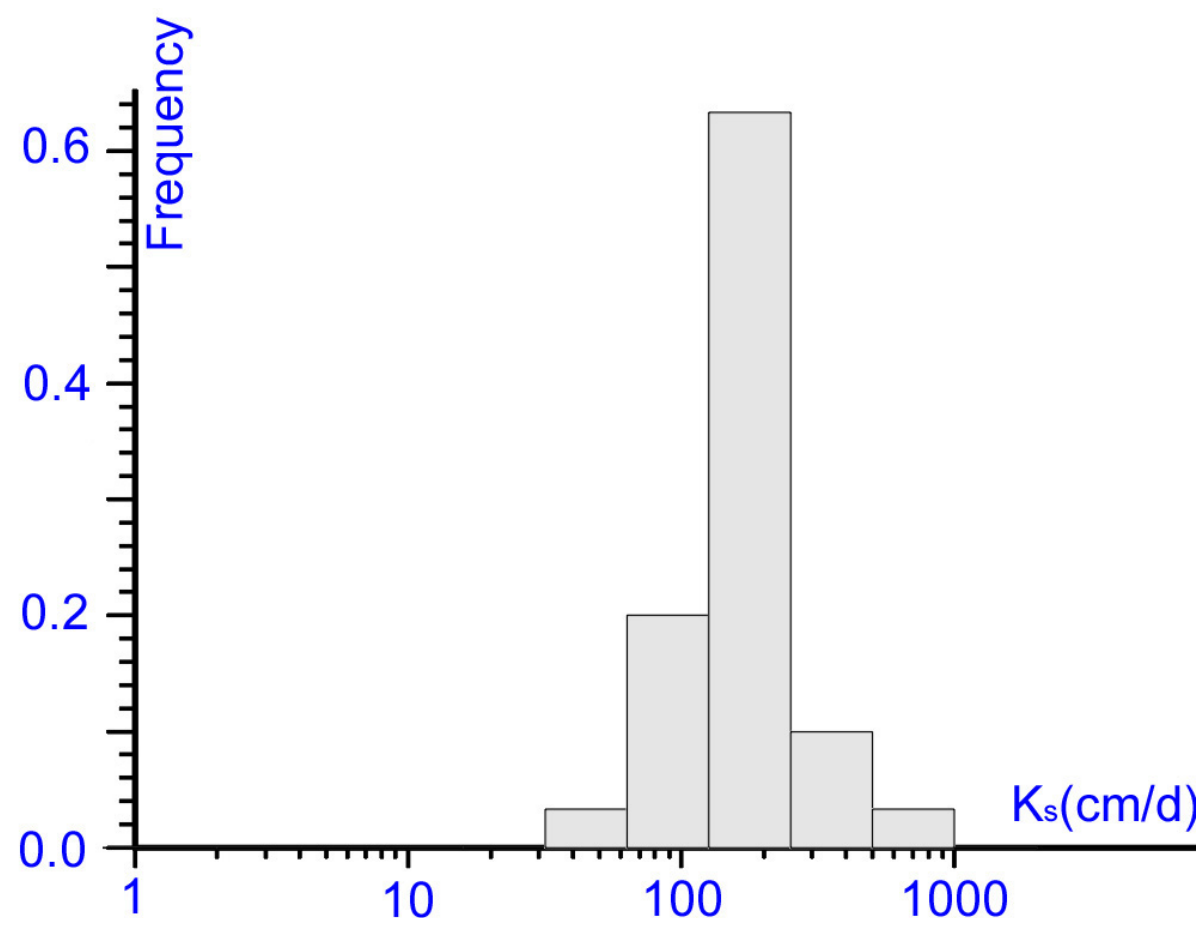

Characterization of field saturated hydraulic conductivity

C. Fallico et al.

Title Page

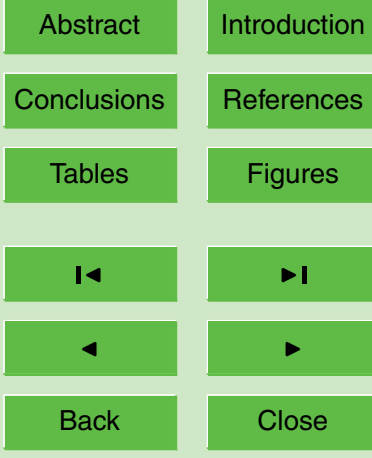

Full Screen / Esc

Fig. 5. (b) Disc infiltrometer data log-histogram.

Print Version

Interactive Discussion 


\section{HESSD}

2, 1247-1298, 2005

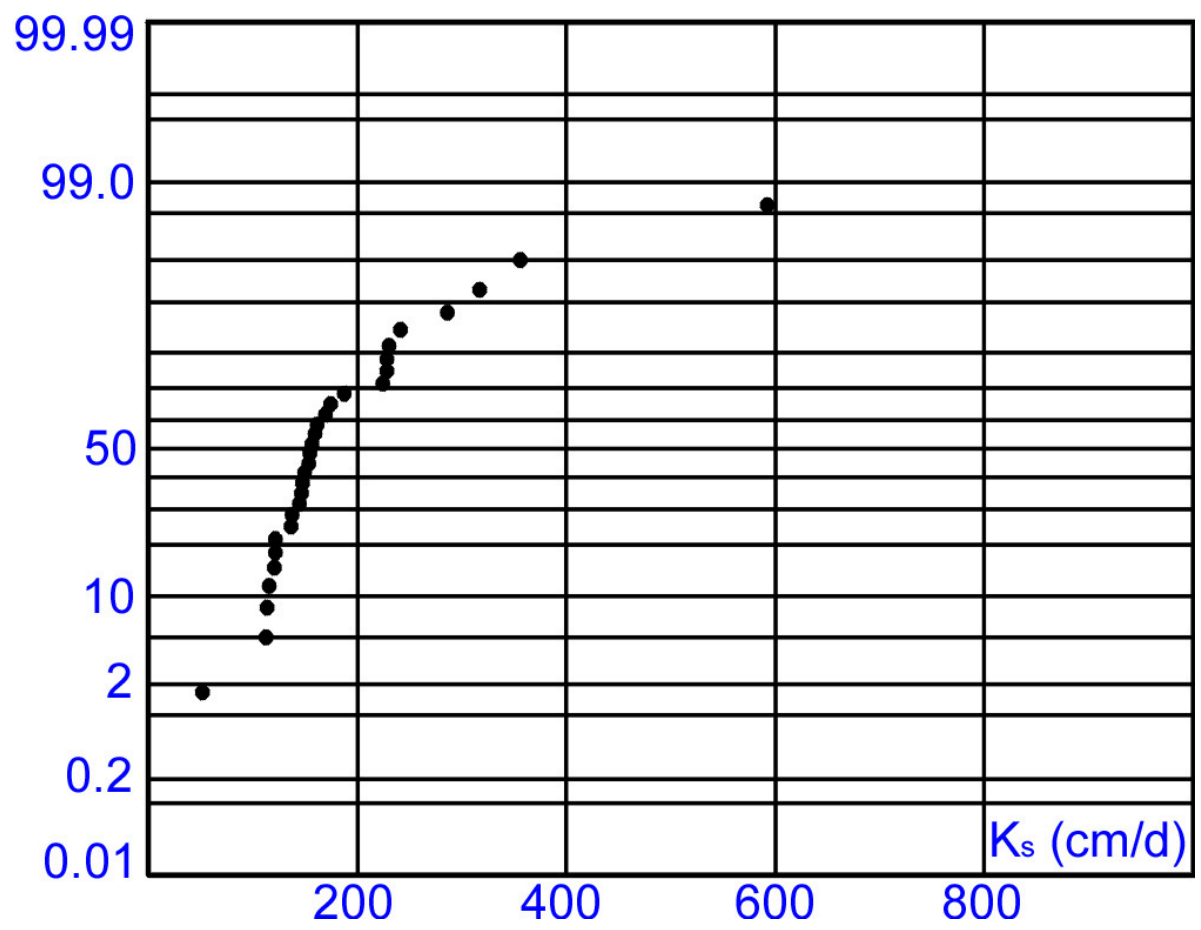

Characterization of field saturated hydraulic conductivity

C. Fallico et al.

\section{Title Page}

Abstract

Introduction

Conclusions

References

Tables

Figures

14

4

Back

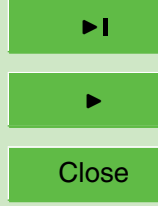

Full Screen / Esc

Fig. 5. (c) Disc infiltrometer data probability plot.

Print Version

Interactive Discussion 
HESSD

2, 1247-1298, 2005

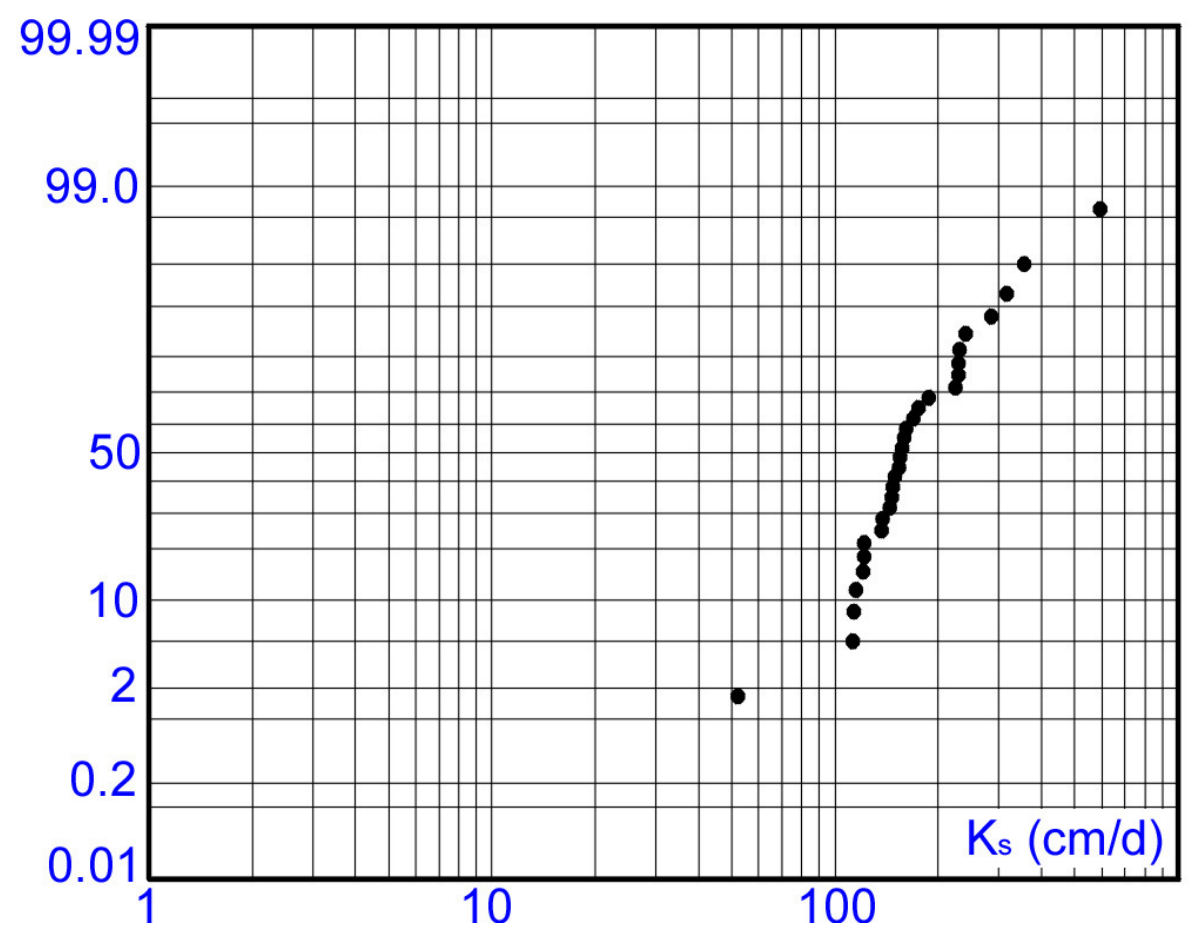

Characterization of field saturated hydraulic conductivity

C. Fallico et al.

Title Page

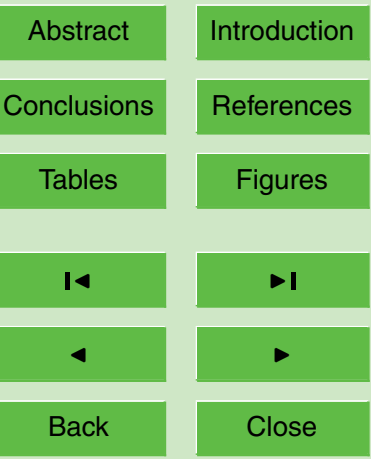

Full Screen / Esc

Fig. 5. (d) Disc infiltrometer data log-probability plot.

Print Version

Interactive Discussion 


\section{HESSD}

2, 1247-1298, 2005

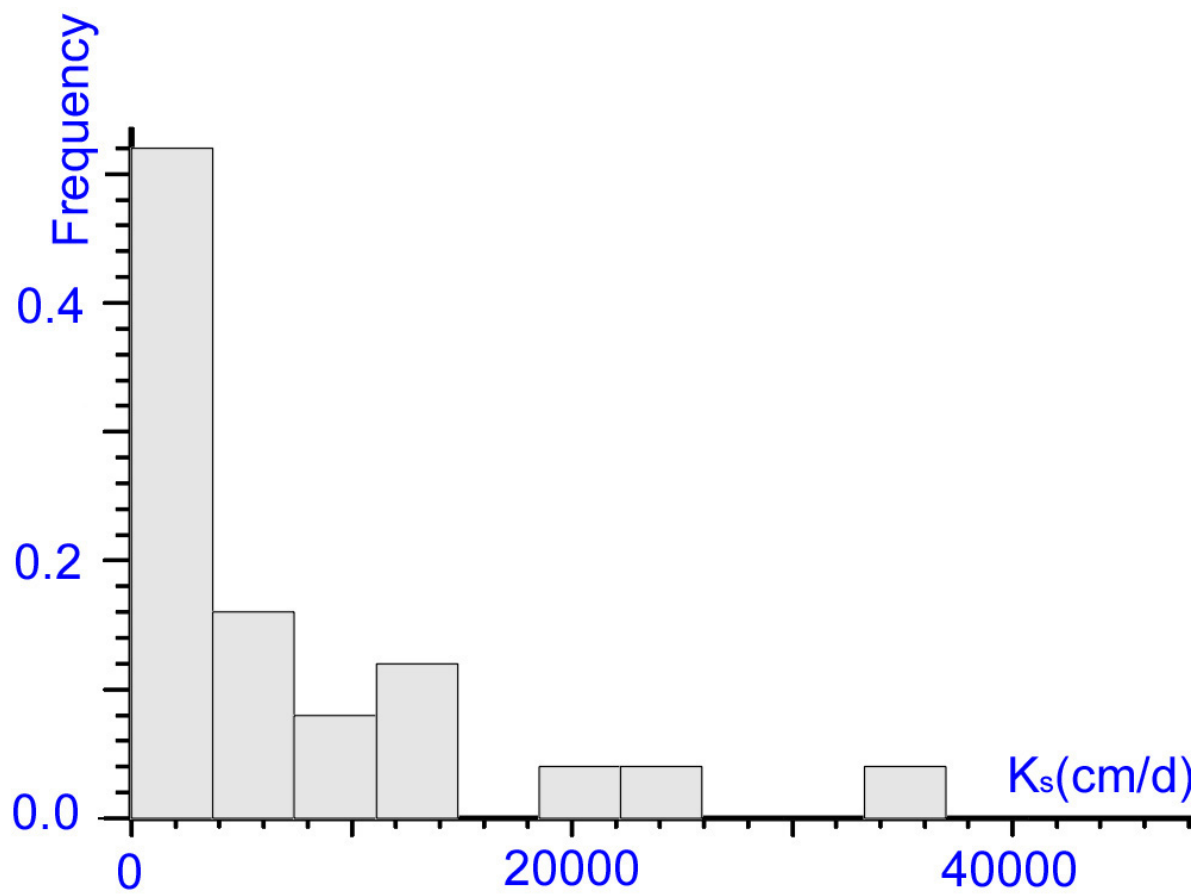

Characterization of field saturated hydraulic conductivity

C. Fallico et al.

Title Page

Abstract

Conclusions

Tables

14

4

Back

Fig. 6. (a) Ring infiltrometer data histogram.

\section{Full Screen / Esc}

Print Version

Interactive Discussion 
HESSD

2, 1247-1298, 2005

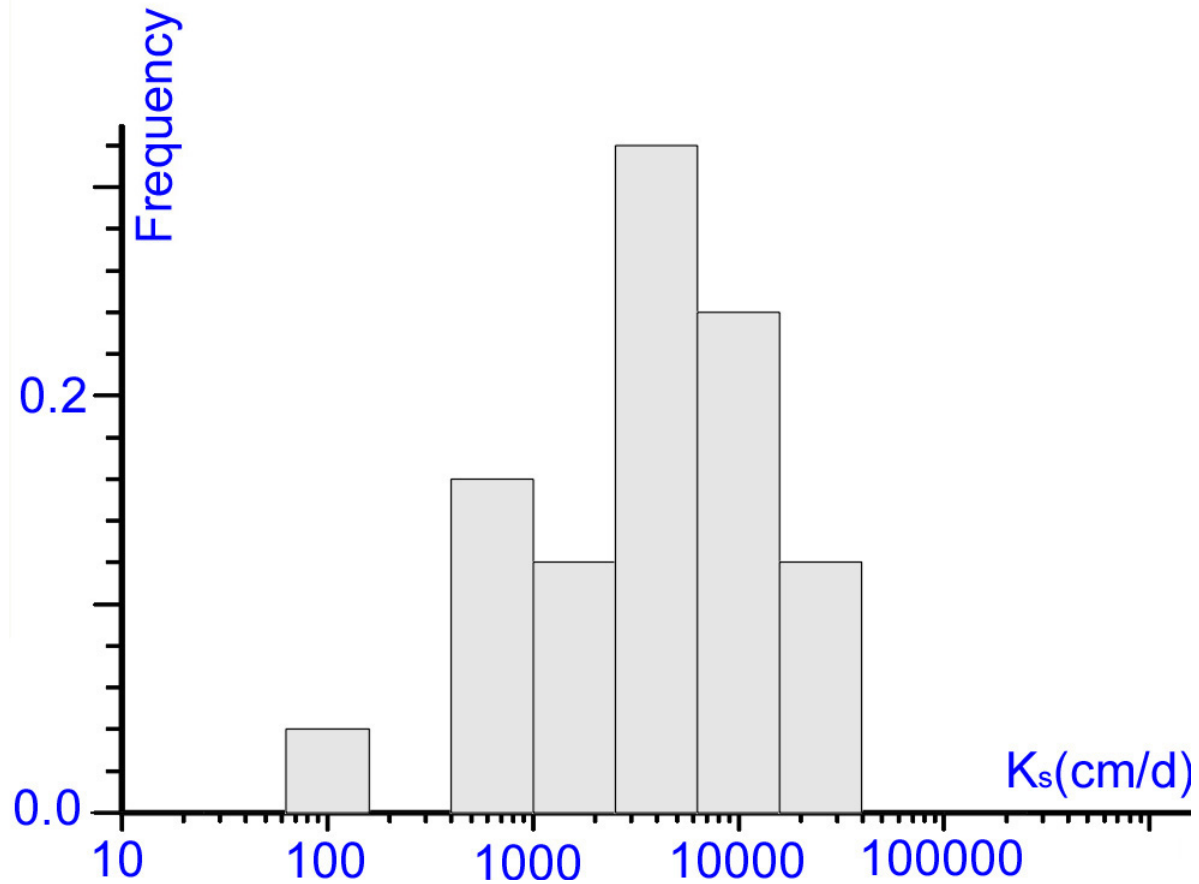

Characterization of field saturated hydraulic conductivity

C. Fallico et al.

Title Page

Abstract

Conclusions

Tables

14

4

Back
Introduction

References

Figures

$\rightarrow 1$

Close

Full Screen / Esc

Fig. 6. (b) Ring infiltrometer data log-histogram.

Print Version

Interactive Discussion 


\section{HESSD}

2, 1247-1298, 2005

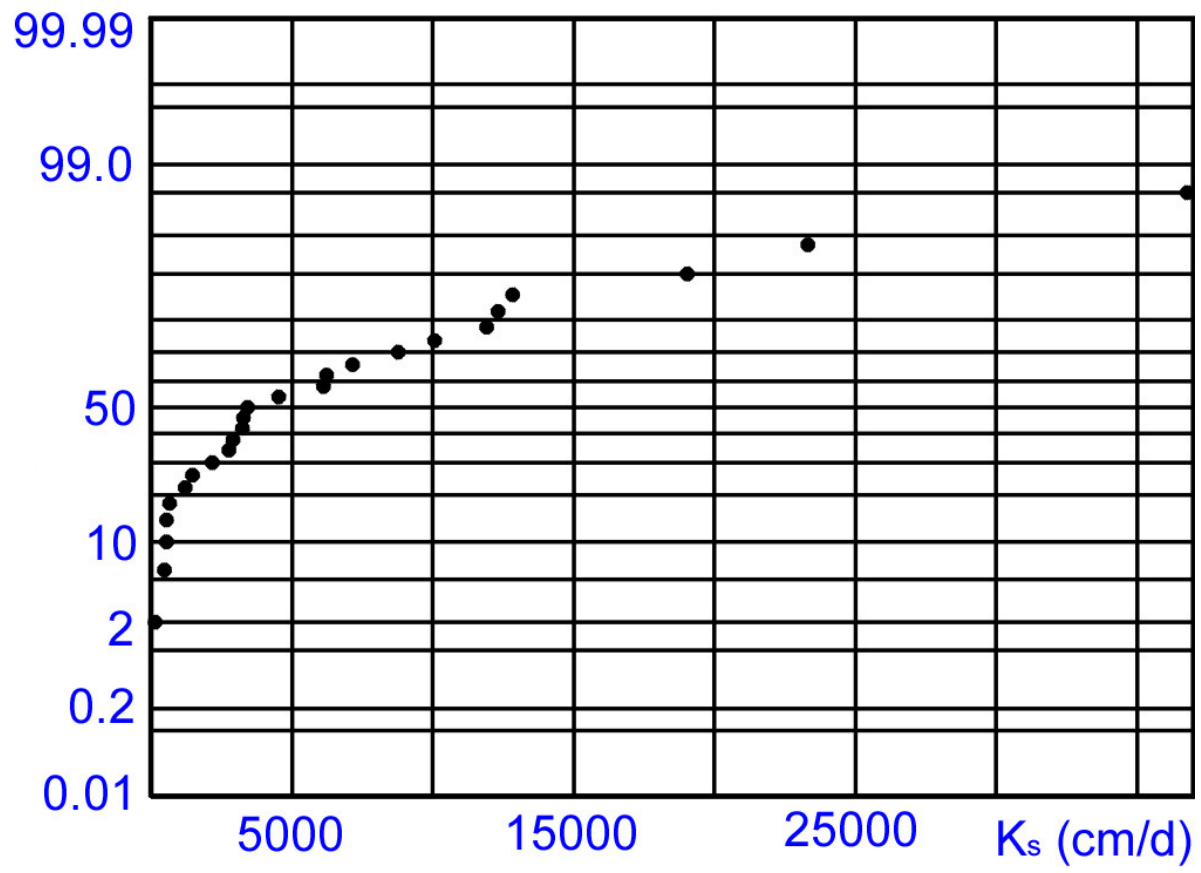

Characterization of field saturated hydraulic conductivity

C. Fallico et al.

\section{Title Page}

Abstract

Introduction

Conclusions

References

Tables

Figures

\section{4}

4

Back

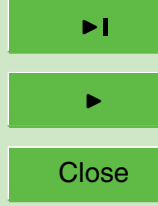

Full Screen / Esc

Fig. 6. (c) Ring infiltrometer data probability plot.

Print Version

Interactive Discussion 
HESSD

2, 1247-1298, 2005

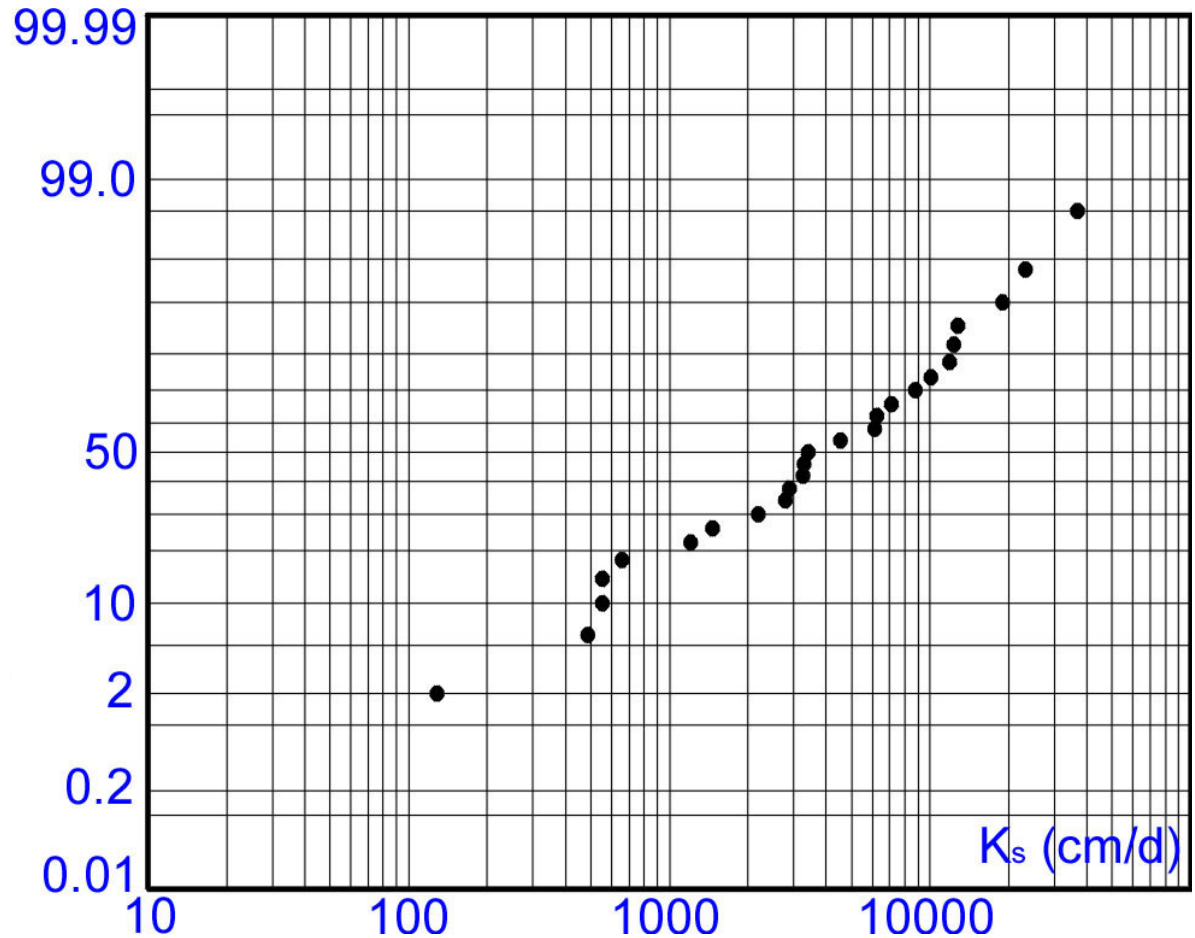

Characterization of field saturated hydraulic conductivity

C. Fallico et al.

Title Page

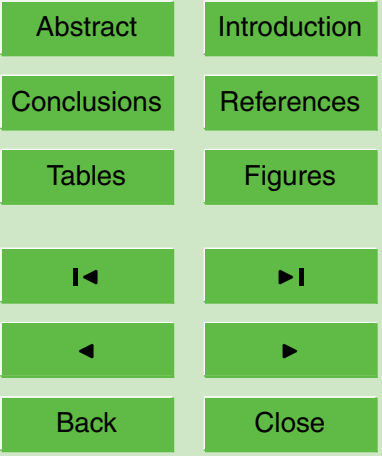

Full Screen / Esc

Print Version

Interactive Discussion 


\section{HESSD}

2, 1247-1298, 2005

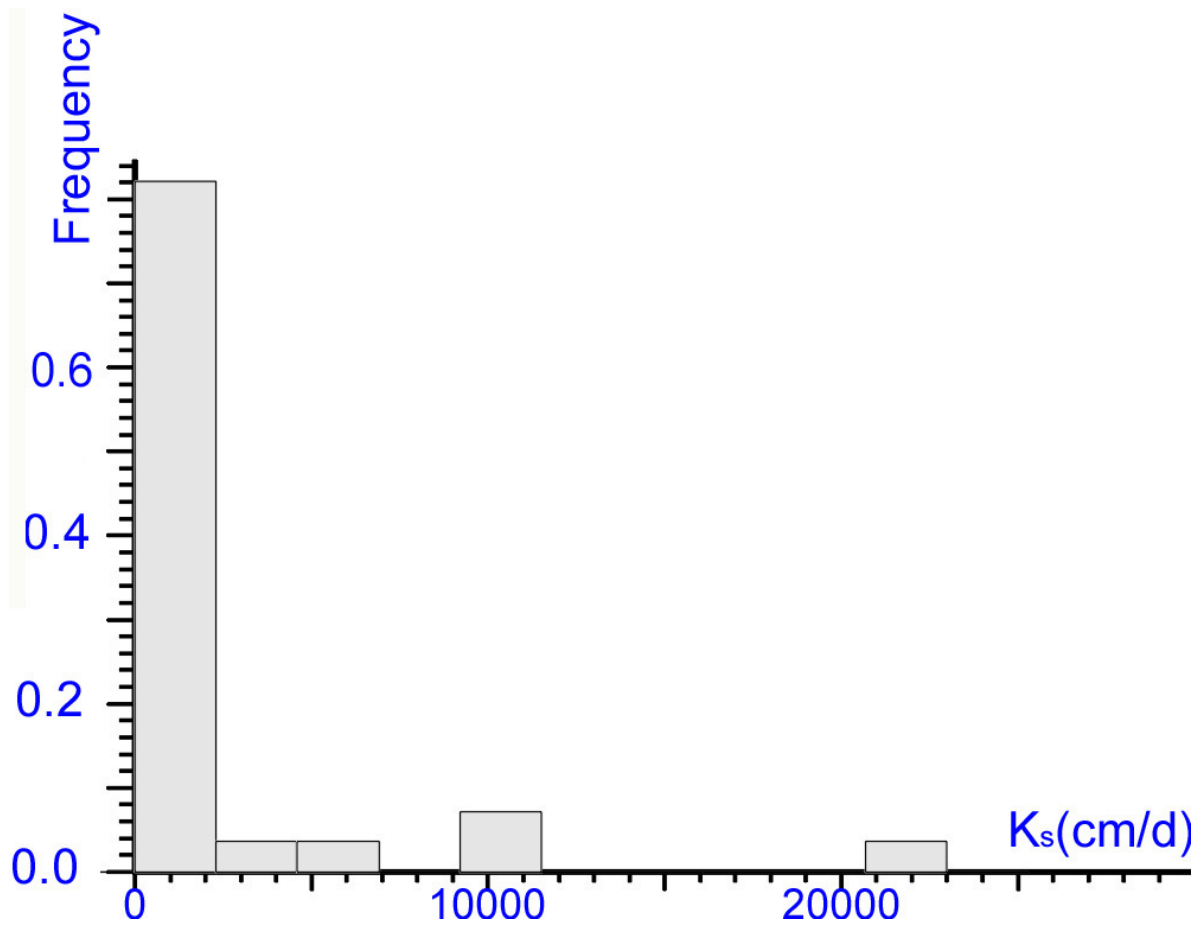

Characterization of field saturated hydraulic conductivity

C. Fallico et al.

Title Page

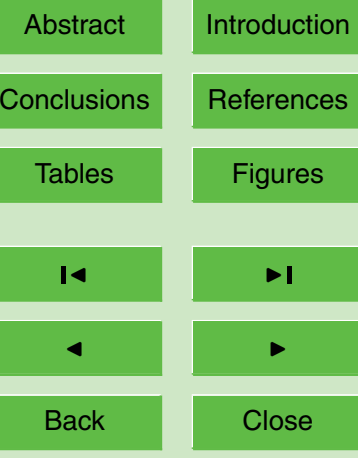

Full Screen / Esc

Fig. 7. (a) Lab data histogram.

Print Version

Interactive Discussion 


\section{HESSD}

2, 1247-1298, 2005

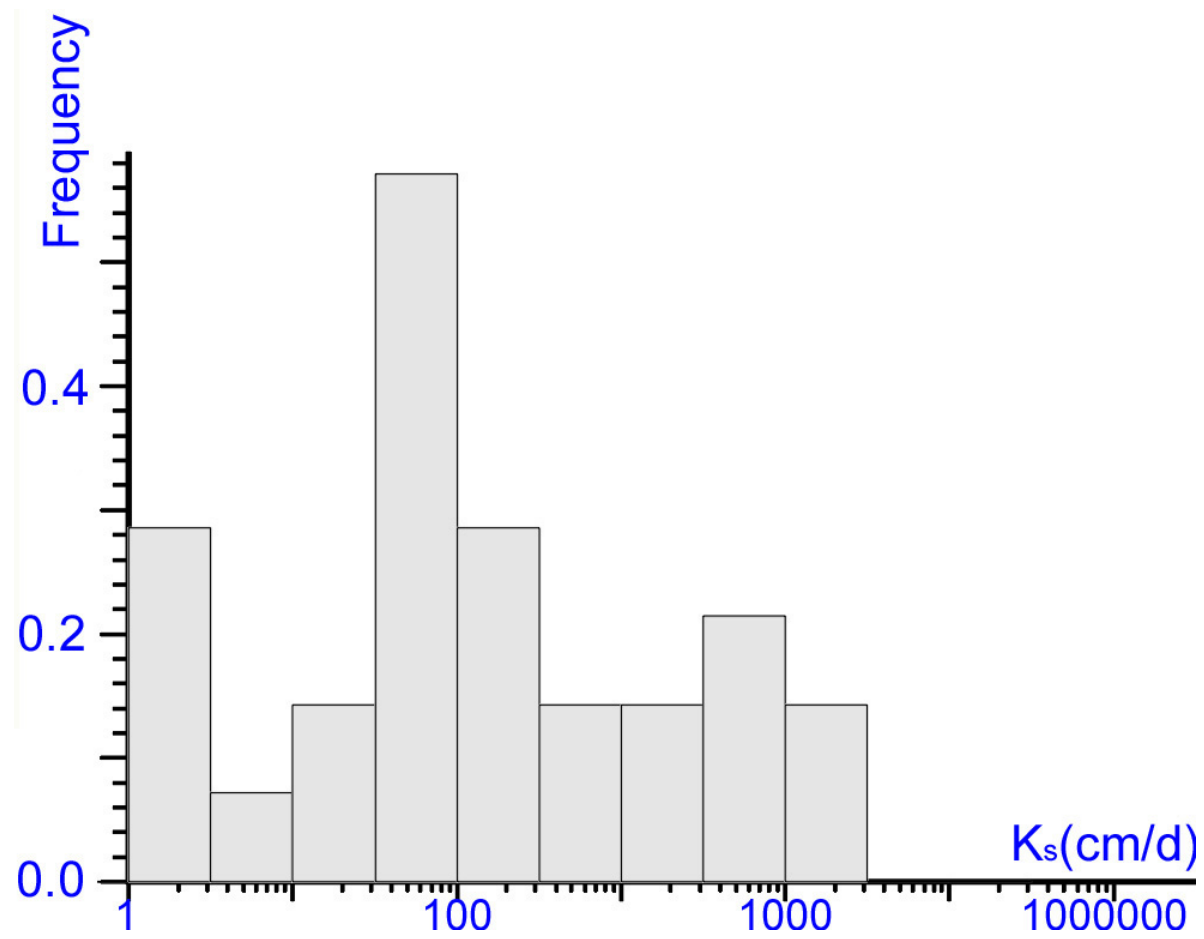

Characterization of field saturated hydraulic conductivity

C. Fallico et al.

Title Page

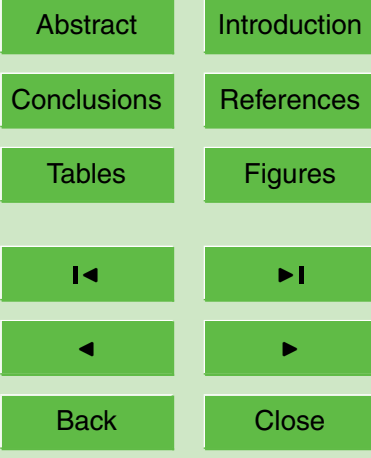

Full Screen / Esc

Print Version

Interactive Discussion 


\section{HESSD}

2, 1247-1298, 2005

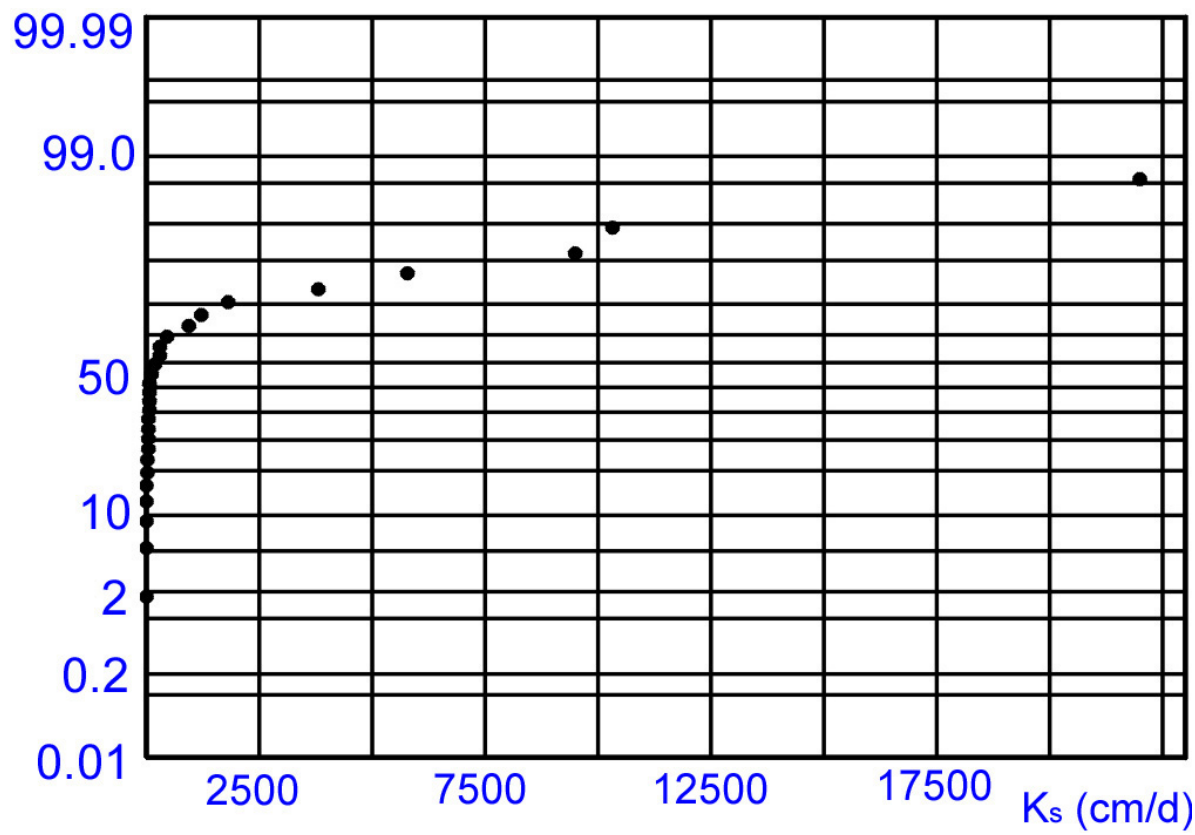

Characterization of field saturated hydraulic conductivity

C. Fallico et al.

Title Page

Abstract

Introduction

Conclusions

References

Tables

Figures

14

$\triangleleft$

Back

Close

Full Screen / Esc

Print Version

Interactive Discussion

\section{EGU}


HESSD

2, 1247-1298, 2005

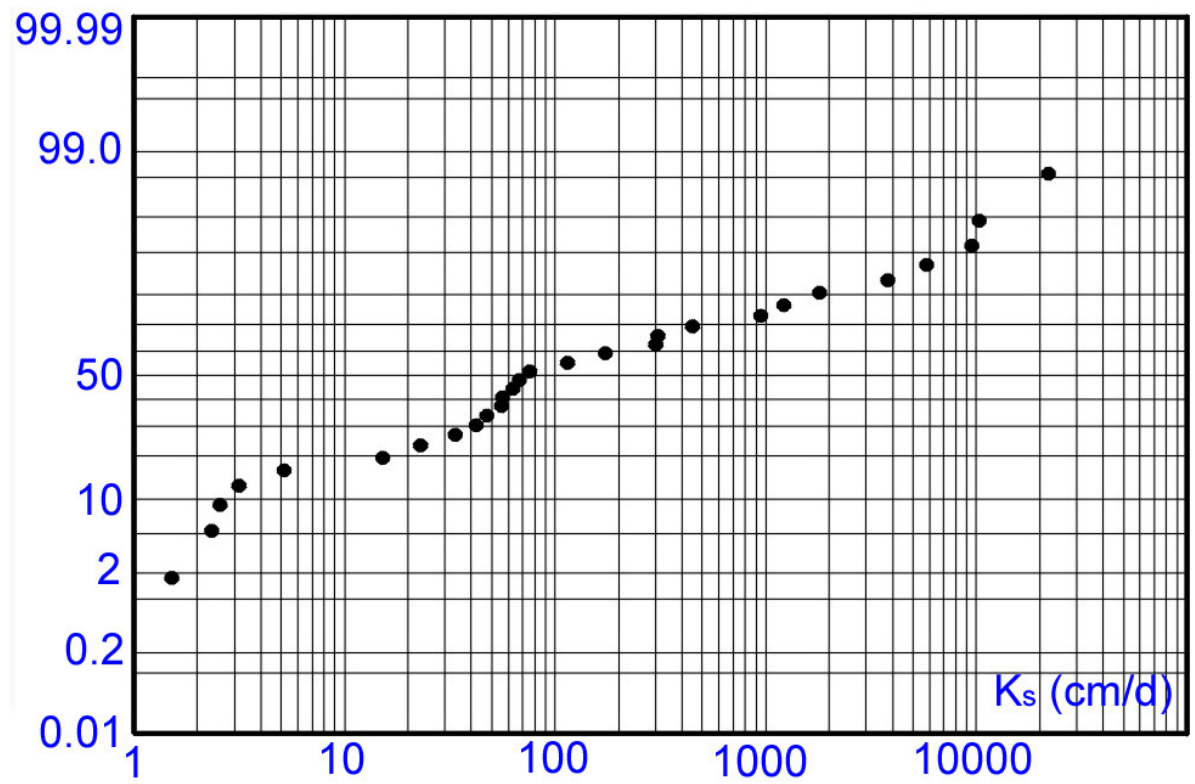

Characterization of field saturated hydraulic conductivity

C. Fallico et al.

Title Page

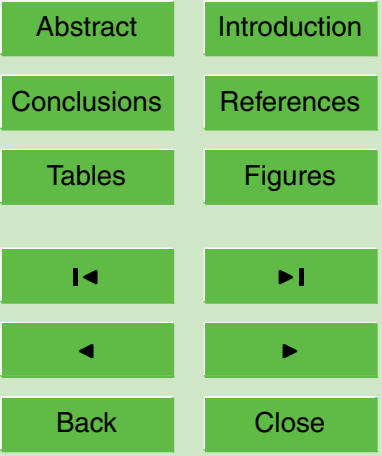

Fig. 7. (d) Lab data log-probability plot.

Full Screen / Esc

Print Version

Interactive Discussion 
HESSD

2, 1247-1298, 2005

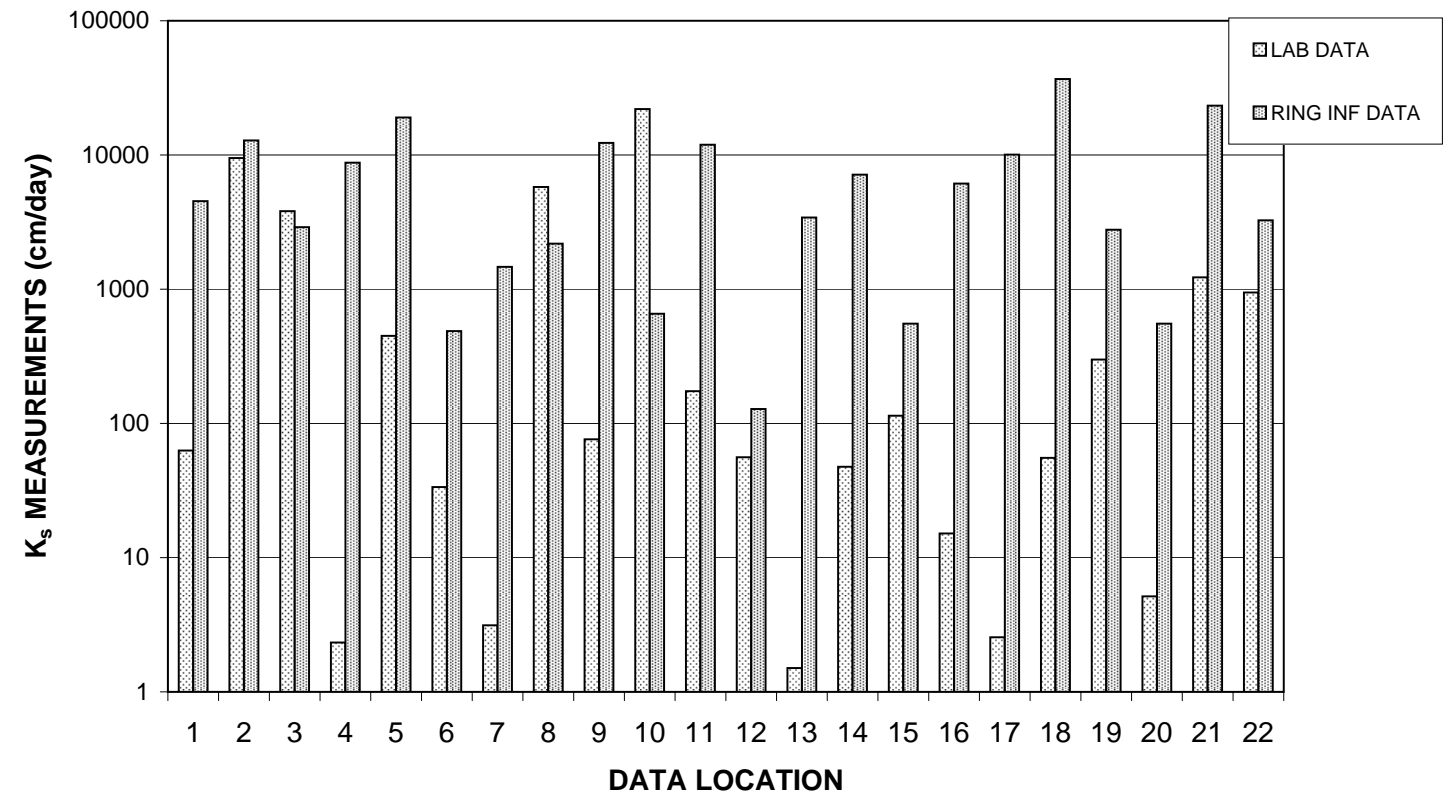

Fig. 8. (a) Comparison between lab and ring infiltrometer $K_{S}$-data values.

Characterization of field saturated hydraulic conductivity

C. Fallico et al.

Title Page

Abstract

Introduction

Conclusions

References

Tables

Figures

14

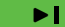

4

Back

Close

Full Screen / Esc

Print Version

Interactive Discussion 
HESSD

2, 1247-1298, 2005

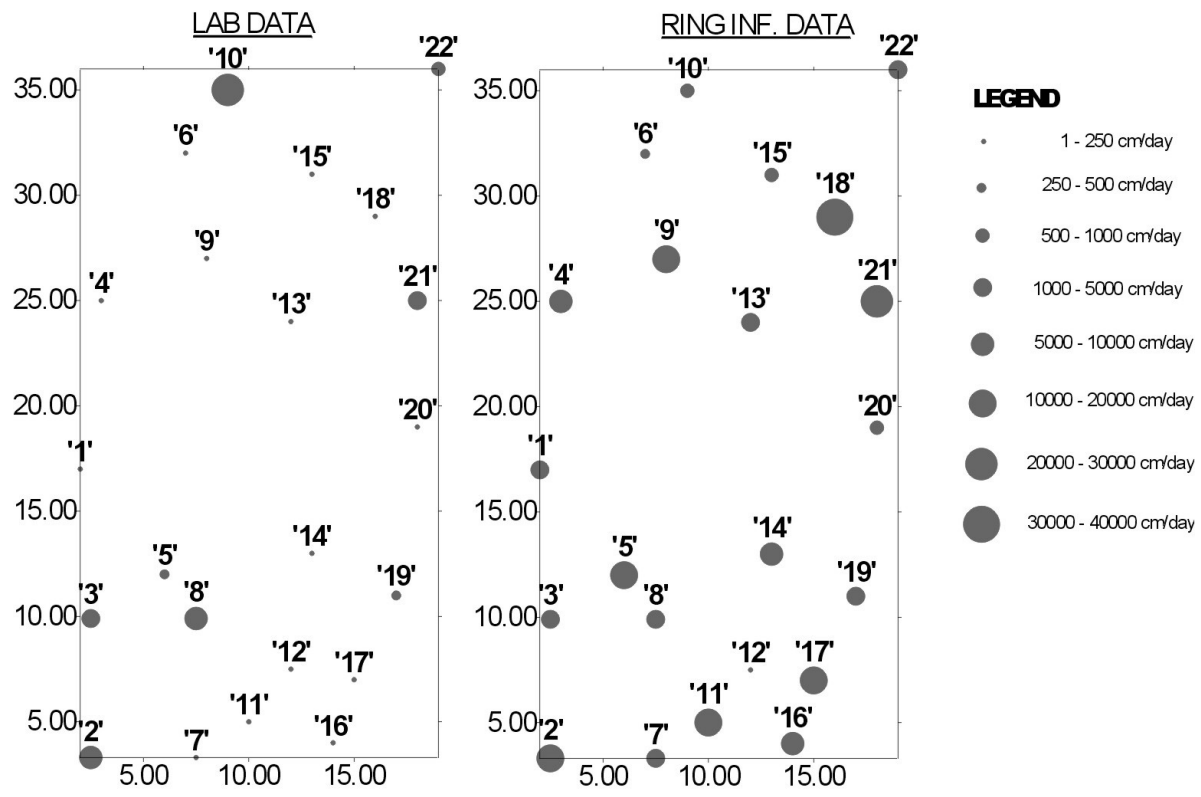

Characterization of field saturated hydraulic conductivity

C. Fallico et al.

Title Page

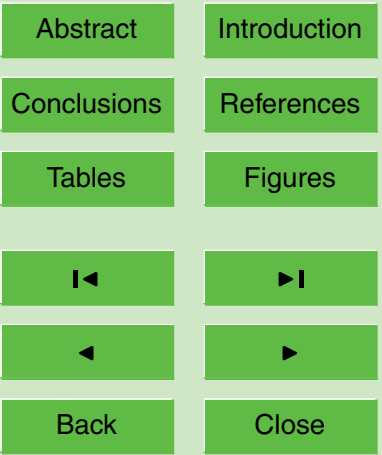

Full Screen / Esc

Print Version

Interactive Discussion 


\section{HESSD}

2, 1247-1298, 2005

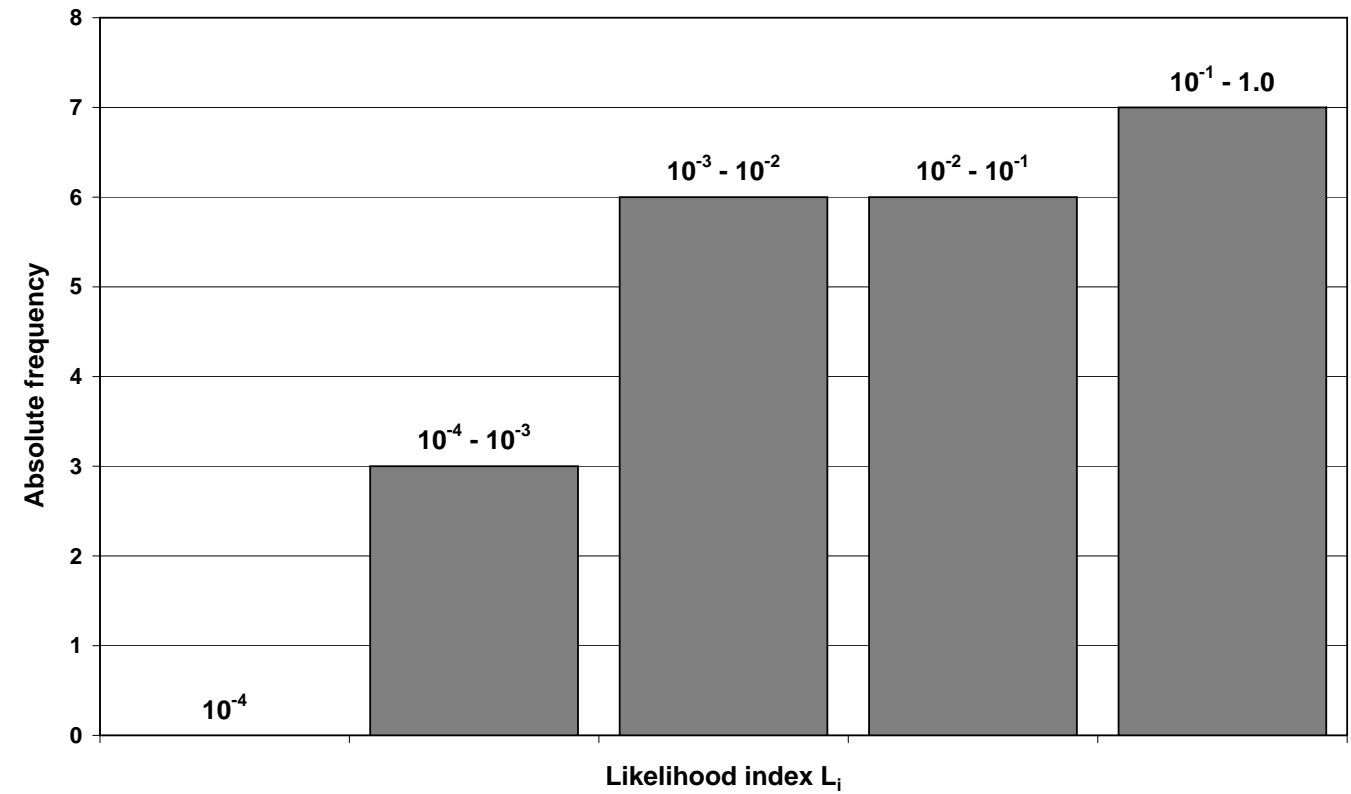

Characterization of field saturated hydraulic conductivity

C. Fallico et al.

Title Page

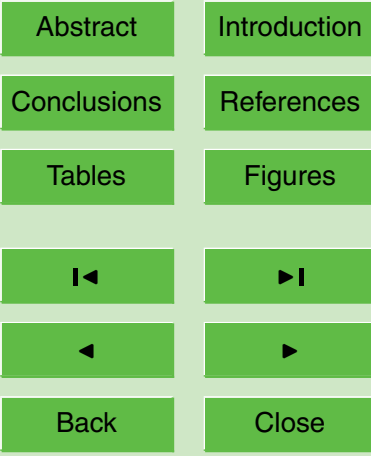

Full Screen / Esc

Print Version

Interactive Discussion 


\section{HESSD}

2, 1247-1298, 2005

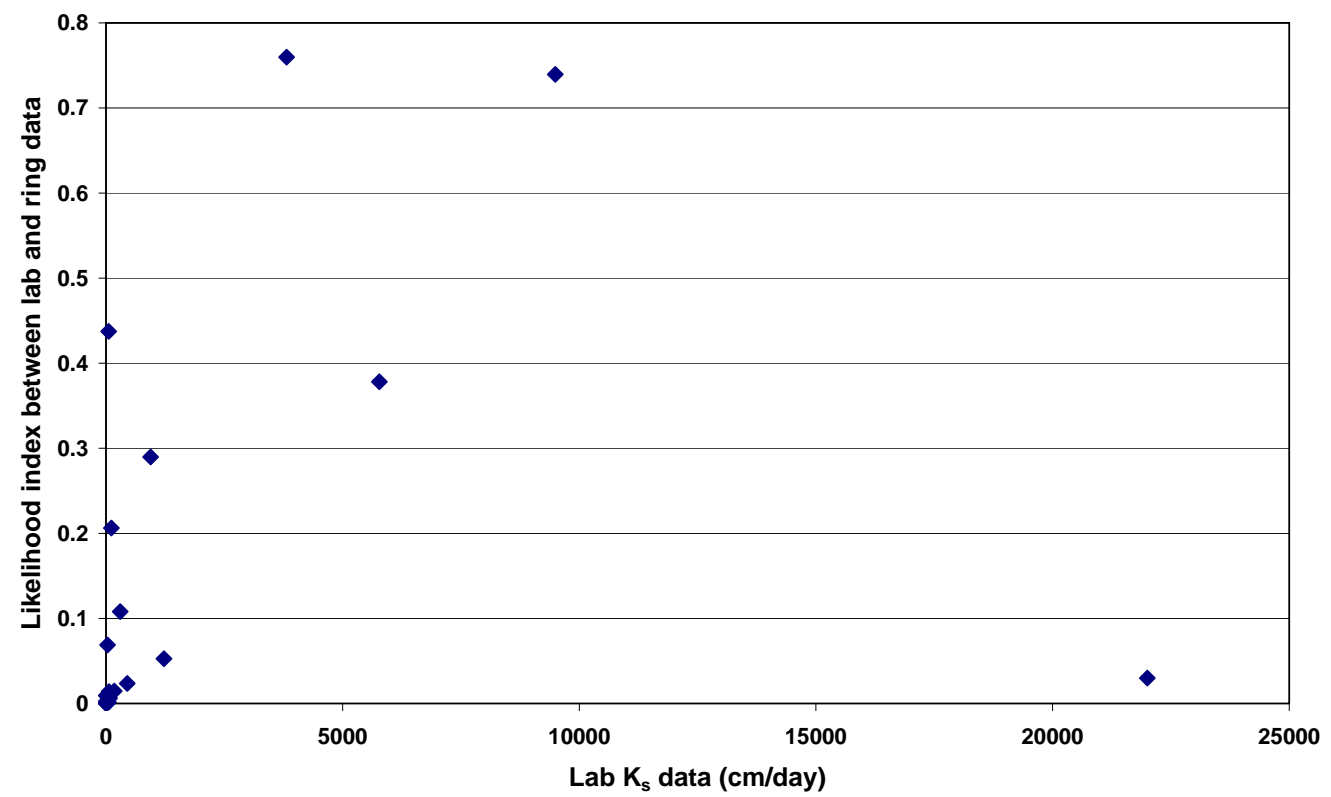

Characterization of field saturated hydraulic conductivity

C. Fallico et al.

Title Page

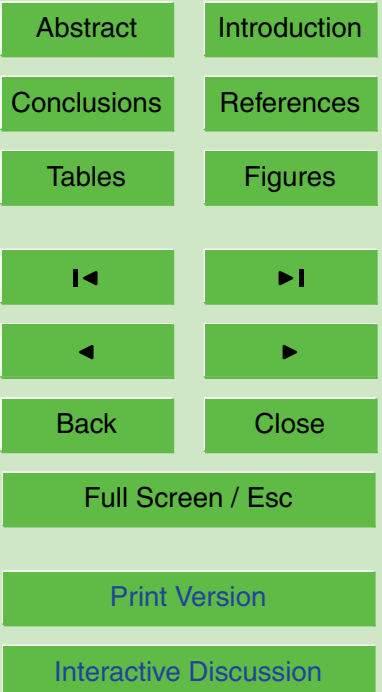




\section{HESSD}

2, 1247-1298, 2005

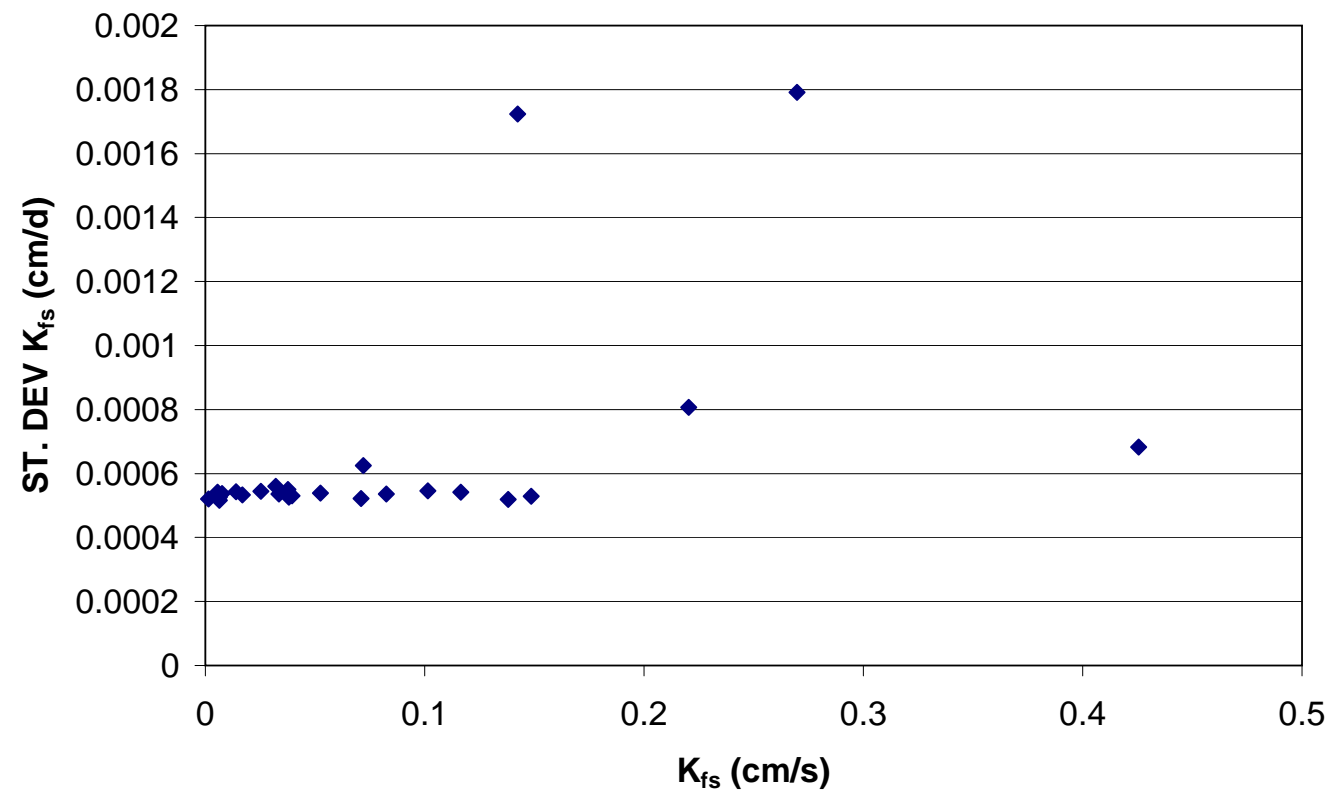

Fig. 10. (a) Ring infiltrometer data sensitivity analysis: $K_{f s}$ standard deviation vs. $K_{f s}$ mean.

Characterization of field saturated hydraulic conductivity

C. Fallico et al.

Title Page

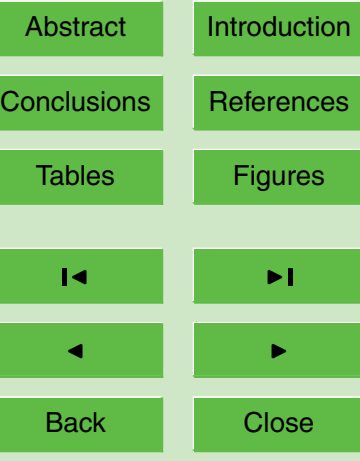

Full Screen / Esc

Print Version

Interactive Discussion 


\section{HESSD}

2, 1247-1298, 2005

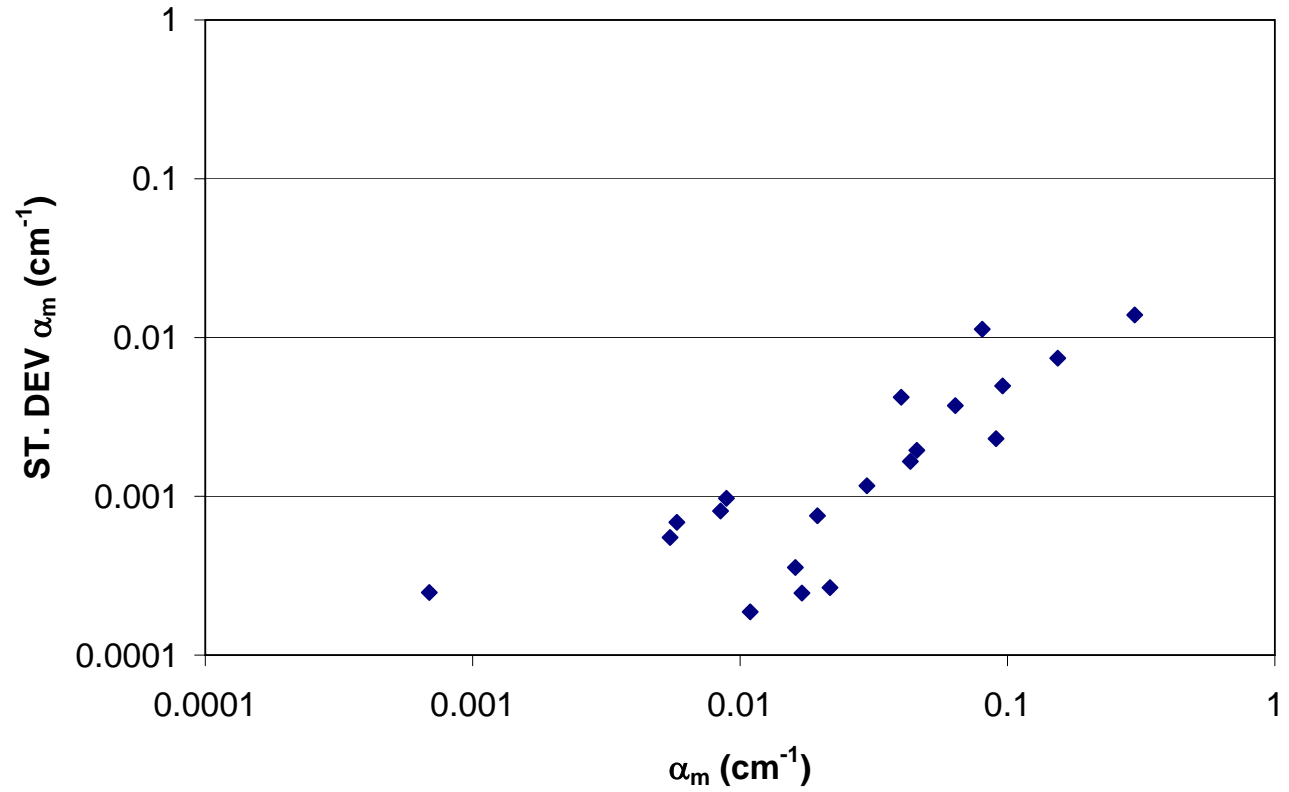

Characterization of field saturated hydraulic conductivity

C. Fallico et al.

Title Page

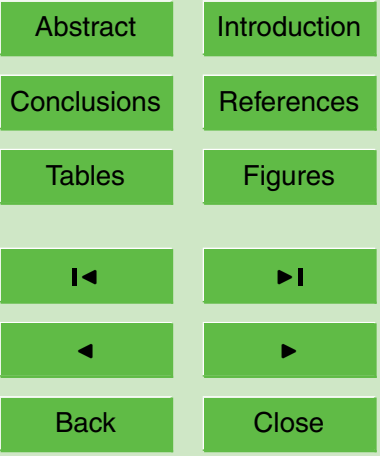

Full Screen / Esc

Print Version

Interactive Discussion 


\section{HESSD}

2, 1247-1298, 2005

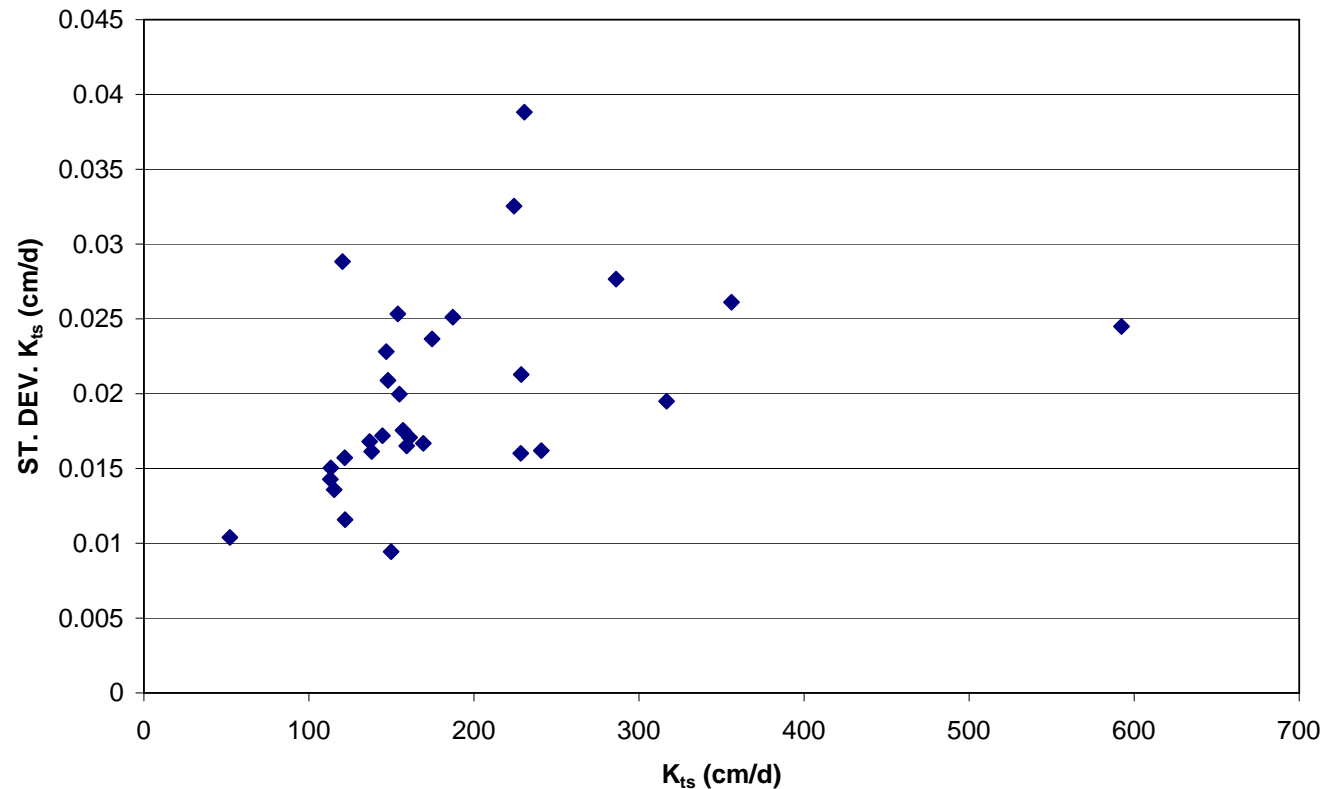

Characterization of field saturated hydraulic conductivity

C. Fallico et al.

Title Page

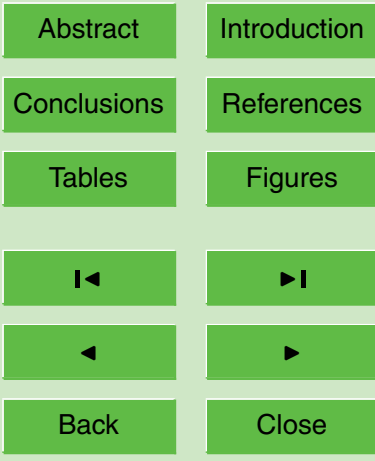

Full Screen / Esc

Fig. 11
values.

Print Version

Interactive Discussion 


\section{HESSD}

2, 1247-1298, 2005

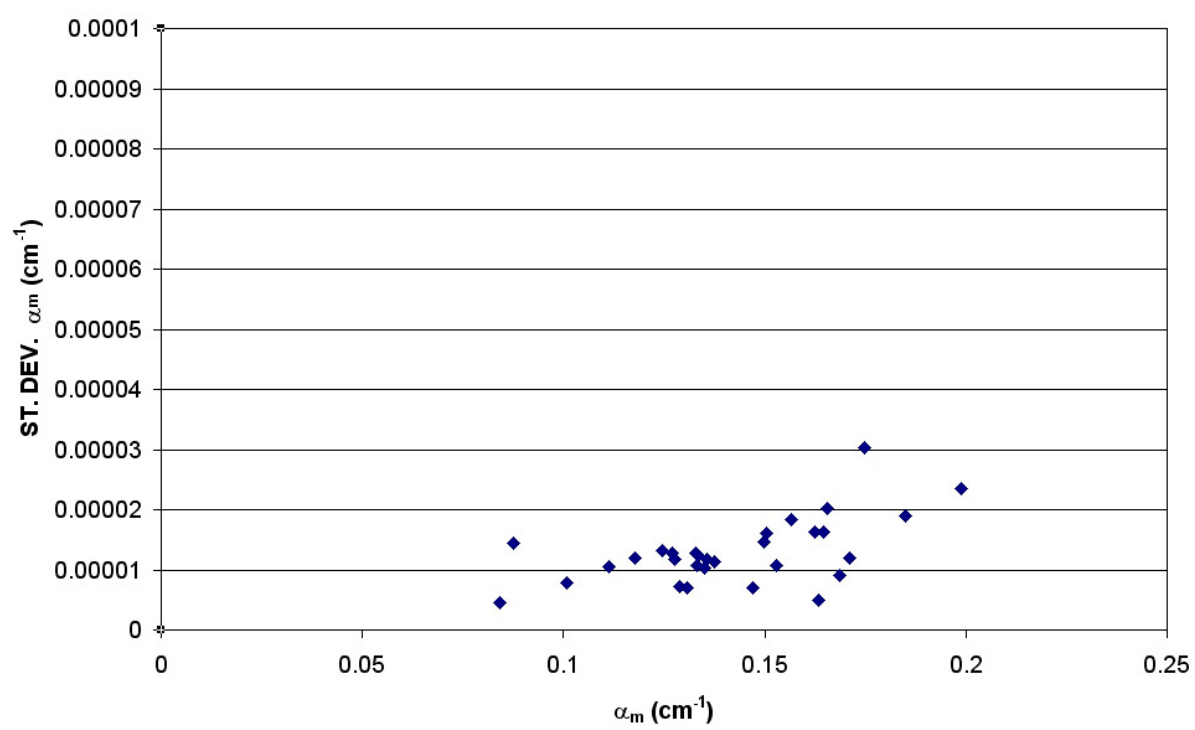

Characterization of field saturated hydraulic conductivity

C. Fallico et al.

Title Page

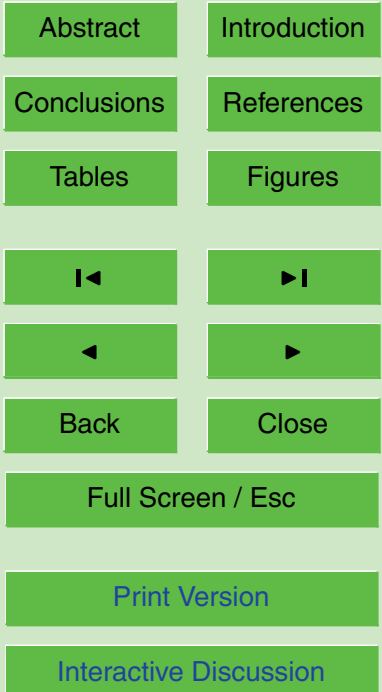

Fig. 11. (b) Disc infiltrometer data sensitivity analysis: $\alpha_{t}$ standard deviation vs. $\alpha_{t}$ mean values. 


\section{HESSD}

2, 1247-1298, 2005

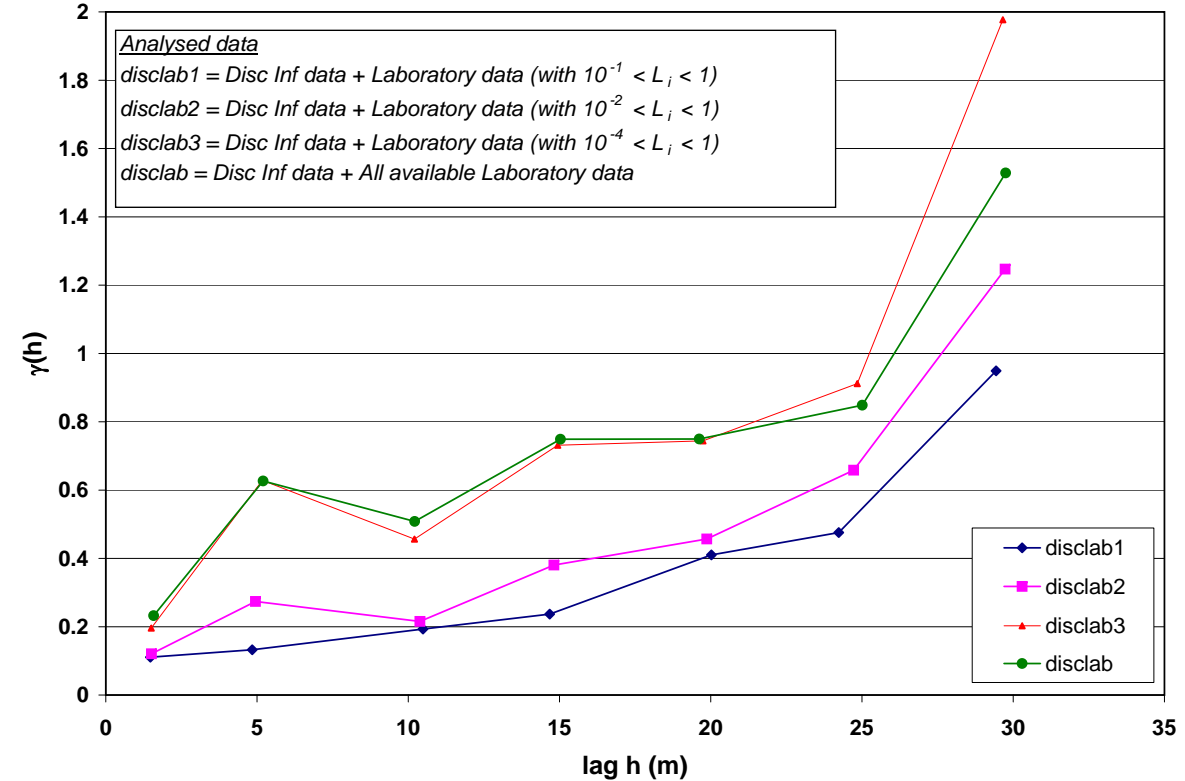

Characterization of field saturated hydraulic conductivity

C. Fallico et al.

Title Page

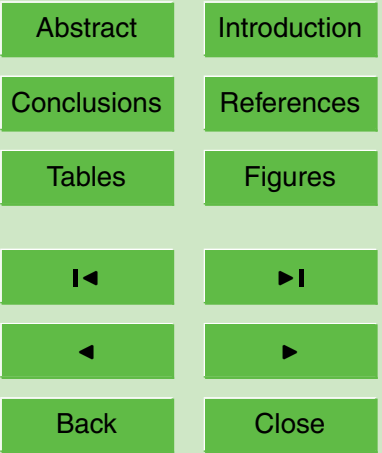

Fig. 12. "Disclab" data sets experimental variograms.

Full Screen / Esc

Print Version

Interactive Discussion 


\section{HESSD}

2, 1247-1298, 2005

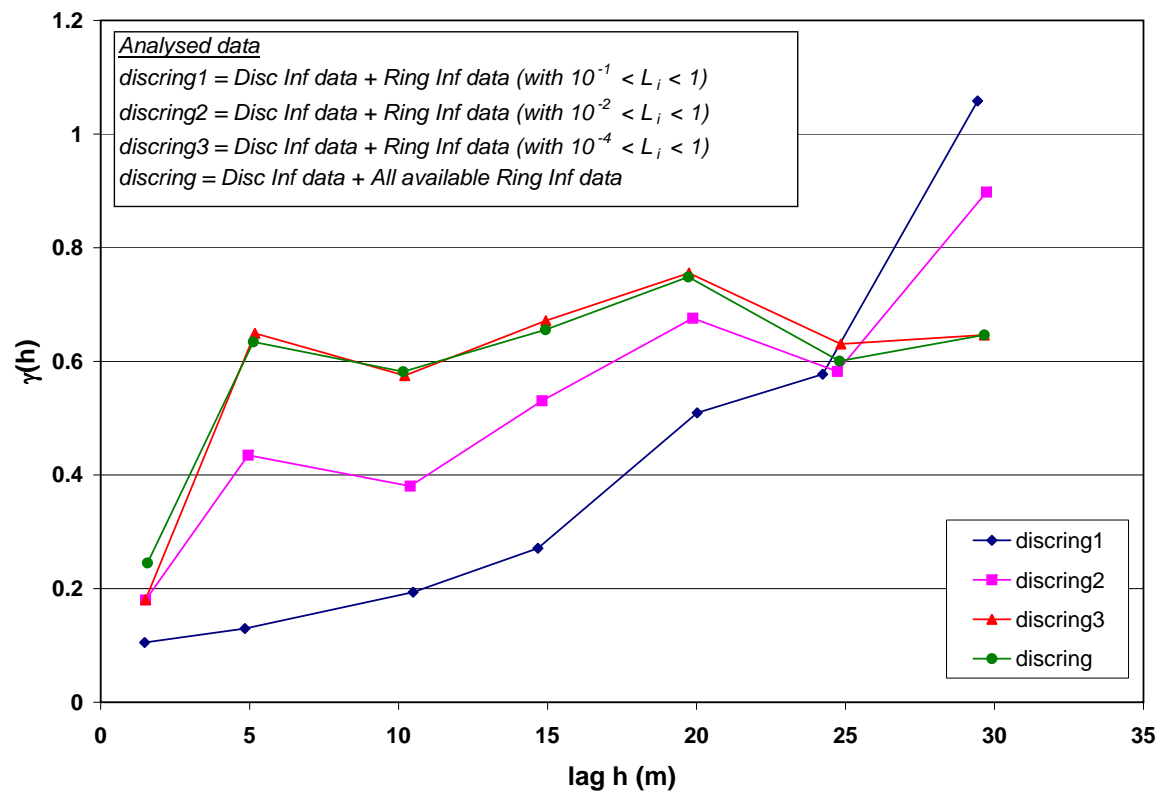

Characterization of field saturated hydraulic conductivity

C. Fallico et al.

Title Page

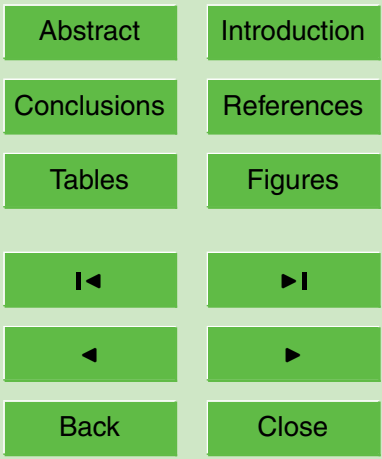

Fig. 13. "Discring" data sets experimental variograms.

Full Screen / Esc

Print Version

Interactive Discussion 


\section{HESSD}

2, 1247-1298, 2005

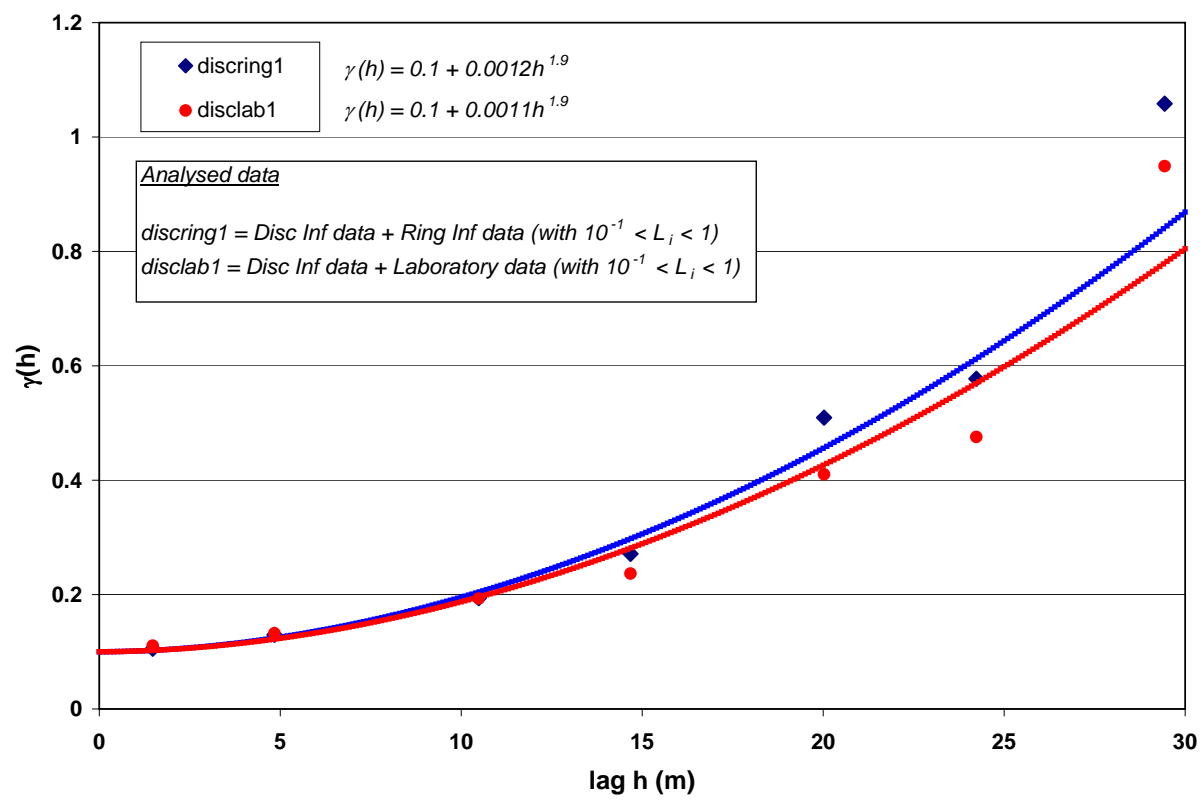

Characterization of field saturated hydraulic conductivity

C. Fallico et al.

Title Page

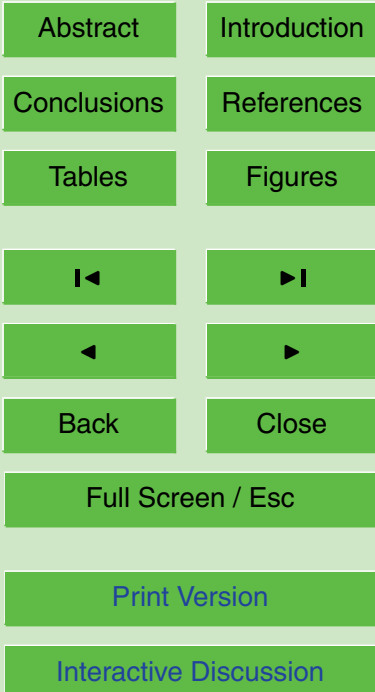




\section{HESSD}

2, 1247-1298, 2005

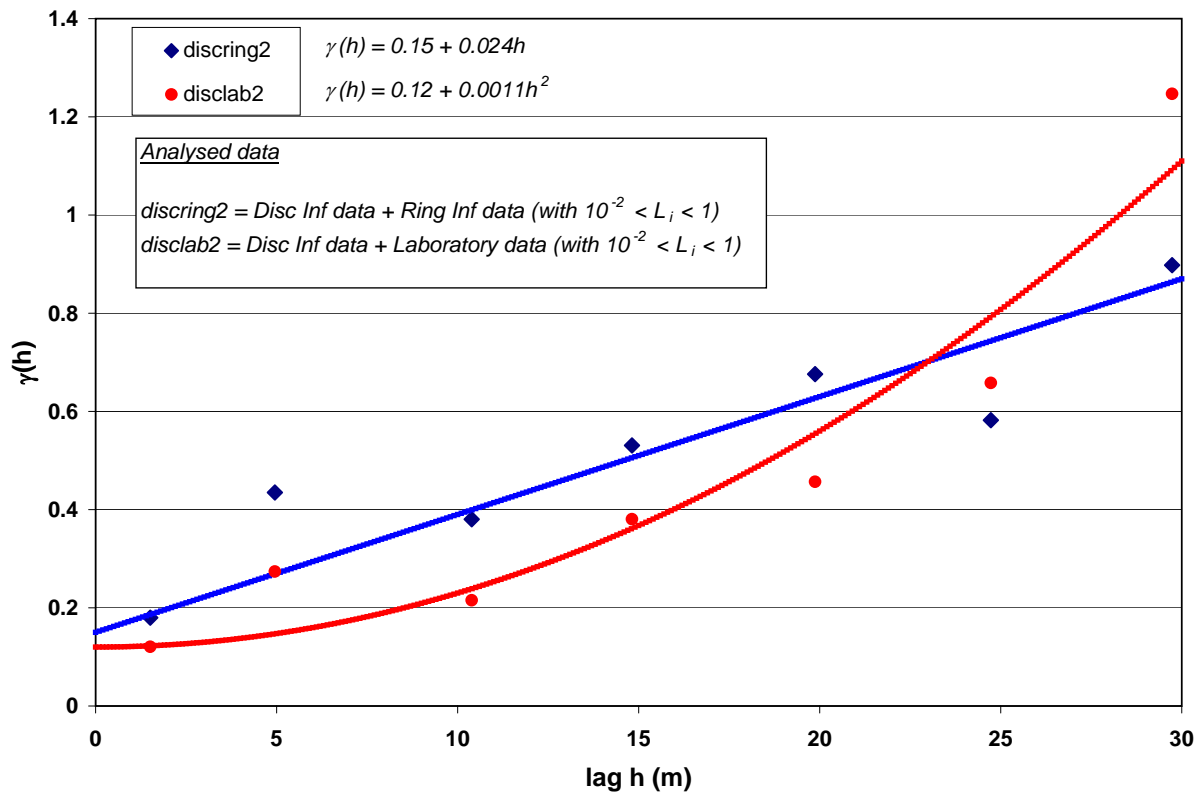

Characterization of field saturated hydraulic conductivity

C. Fallico et al.

Title Page

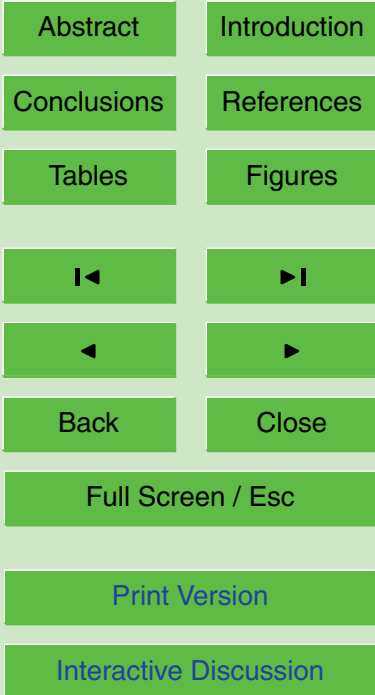




\section{HESSD}

2, 1247-1298, 2005

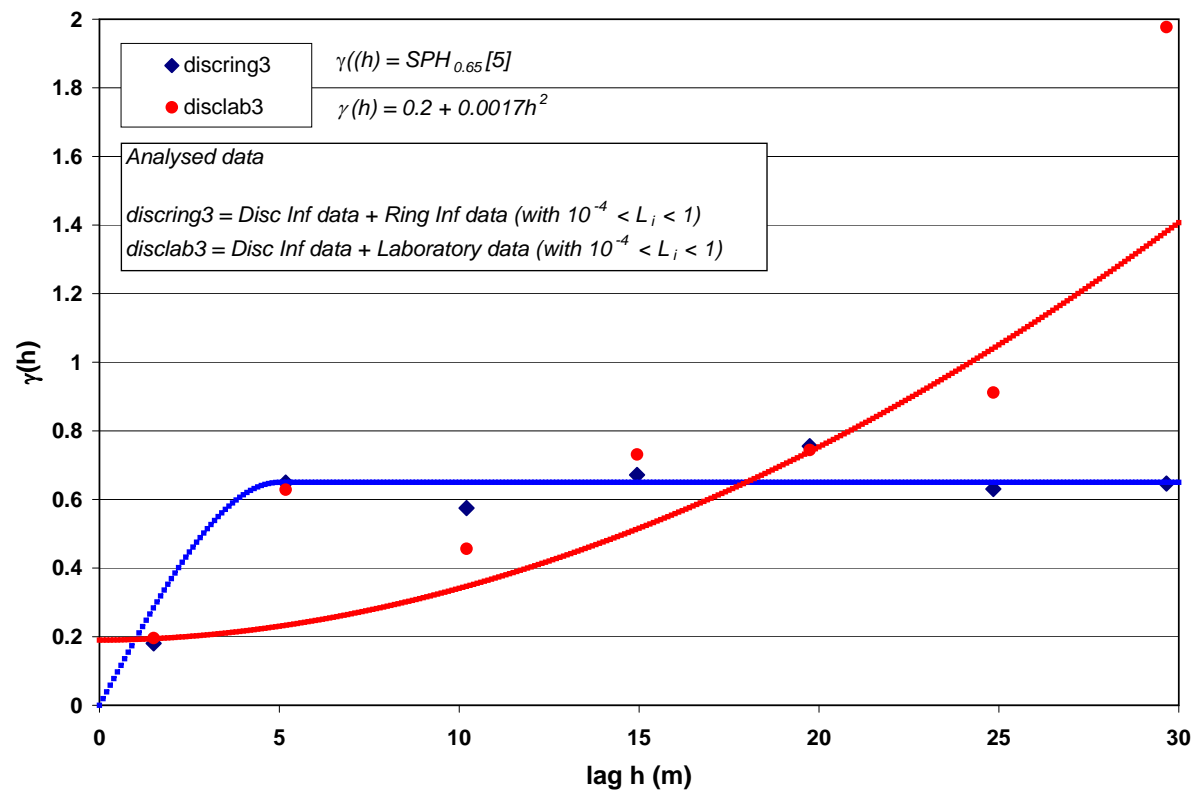

Characterization of field saturated hydraulic conductivity

C. Fallico et al.

Title Page

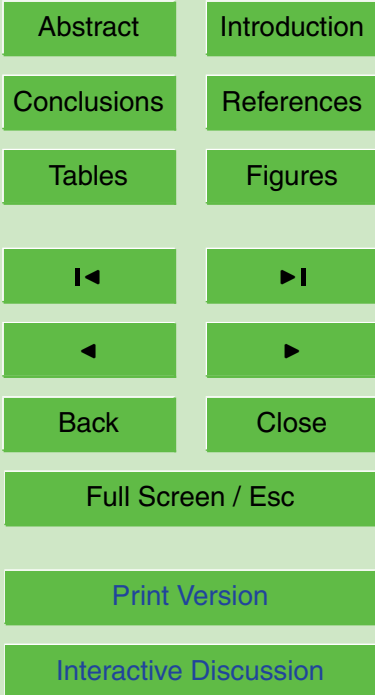




\section{HESSD}

2, 1247-1298, 2005

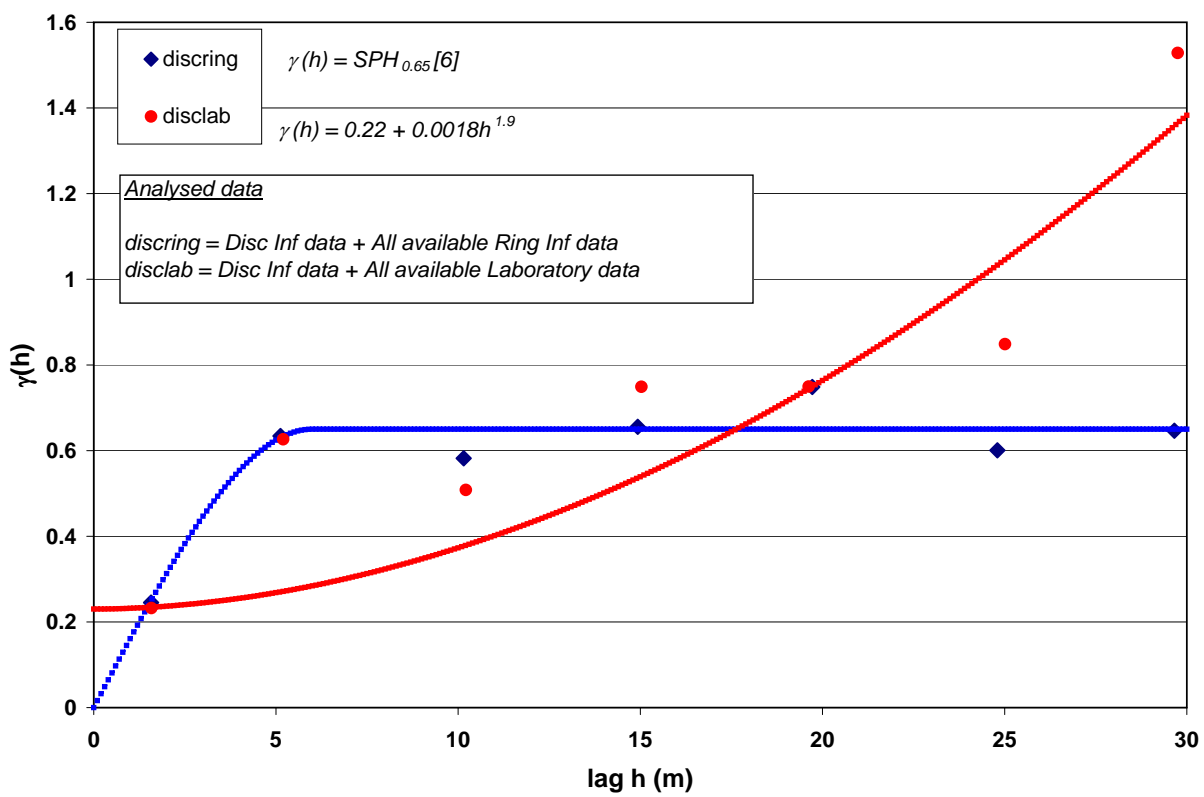

Characterization of field saturated hydraulic conductivity

C. Fallico et al.

Title Page

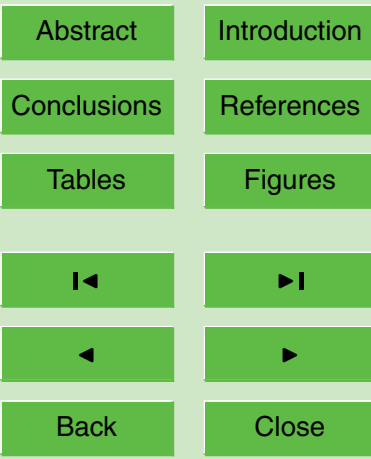

Full Screen / Esc

Print Version

Interactive Discussion 